\title{
Amphiphilic branched polymeric nitroxides for efficient magnetic resonance imaging of multiple- object in vivo
}

\section{Xiaoming Wang}

Sichuan University West China Hospital; Chongqing General Hospital

\section{Shiwei Guo}

Southwest Medical University

\section{Zhiqian Li}

Sichuan University West China Hospital

Qiang Luo

Sichuan University West China Hospital

\section{Yan Dai}

Southwest Medical University

Hu Zhang

Keck Graduate Institute

\section{Qiyong Gong}

Sichuan University West China Hospital

Kui Luo ( $\sim$ luokui@scu.edu.cn )

Sichuan University West China Hospital

\section{Research}

Keywords: Metal free contrast agents, nitroxides, magnetic resonance imaging, polymers

Posted Date: January 27th, 2021

DOI: https://doi.org/10.21203/rs.3.rs-154115/v1

License: (c) (1) This work is licensed under a Creative Commons Attribution 4.0 International License. Read Full License

Version of Record: A version of this preprint was published at Journal of Nanobiotechnology on July 9th, 2021. See the published version at https://doi.org/10.1186/s12951-021-00951-z. 
Amphiphilic branched polymeric nitroxides for efficient magnetic resonance imaging of multiple-object in vivo

Xiaoming Wang ${ }^{1,3^{\dagger}}$, Shiwei Guo ${ }^{4,5^{\dagger}}$, Zhiqian $\mathrm{Li}^{1}$, Qiang Luo ${ }^{1}$, Yan Dai ${ }^{4,5}$, Hu Zhang ${ }^{6}$, Qiyong Gong ${ }^{1,2}$ and Kui Luo ${ }^{1,2 *}$

1. Huaxi MR Research Center (HMRRC), Department of Radiology, West China Hospital, Functional and molecular imaging Key Laboratory of Sichuan Province, Sichuan University, Chengdu, 610041, China

2. Research Unit of Psychoradiology, Chinese Academy of Medical Sciences, Chengdu, 610041, China

3. Department of Radiology, Chongqing General Hospital, University of Chinese Academy of Sciences (UCAS), 104 Pipashan Zheng Street Chongqing 400014, P. R. China

4. Department of Pharmacy of the Affiliated Hospital of Southwest Medical University, Southwest Medical University, Luzhou, Sichuan Province, 646000, P. R. China

5. Nuclear Medicine and Molecular Imaging Key Laboratory of Sichuan Province, Luzhou, 646000, P. R. China

6. Amgen Bioprocessing Centre, Keck Graduate Institute Claremont, CA 91711, USA

†Dr. Xiaoming Wang and Shiwei Guo contributed equally to this study.

*Corresponding author, E-mail: luokui@scu.edu.cn 


\begin{abstract}
Background: In order to solve the potential toxicity of metal-based Magnetic resonance imaging (MRI) contrast agents (CAs), a concept of non-metallic MRI CAs has emerged. Currently, paramagnetic nitroxides (such as $(2,2,5$, 5-tetramethylpyrrolidine-1-oxyl, PROXYL), (2, 2, 6, 6-tetramethylpiperidine-1-oxide, TEMPO), etc.) are being extensively studied because their good stability and imaging mechanism are similar to metal based contrast agents (such as $\mathrm{Gd}^{3+}$ chelate-based clinical CAs). However, nitroxides lower relaxivity and metabolizes rapidly in vivo are still challenge. Previous researches have proven that the construction of macromolecular nitroxides contrast agents (mORCAs) is a promising solution through the macromolecularization of nitroxides (ie, large molecules carry nitroxides). Macromolecular effects not only improve the stability of nitroxides by limiting their exposure to reductive substances in the body, but also improve the overall ${ }^{1} \mathrm{H}$ water relaxation by increasing the concentration of nitroxides and slowing the molecular rotation speed.
\end{abstract}

Results: Branched pDHPMA-mPEG-Ppa-PROXYL with high molecular weight $(\mathrm{MW}=160 \mathrm{kDa})$ and nitroxides content $(0.059 \mathrm{mmol} / \mathrm{g})$, it can form a nanoscale $(\sim 28$ $\mathrm{nm}$ ) self-assembled aggregate in a water environment and hydrophobic PROXYL can be protected by the hydrophilic outer layer to obtain the strong reduction resistance in vivo. Compared with the small molecular 3-Carboxy-PROXYL (3-CP), Branched pDHPMA-mPEG-Ppa-PROXYL displays there prominent performance: 1) its longitudinal relaxivity $\left(0.50 \mathrm{mM}^{-1} \mathrm{~s}^{-1}\right)$ is about three times that of the 3-CP $(0.17$ $\left.\mathrm{mM}^{-1} \mathrm{~s}^{-1}\right)$; 2) the blood retention time of nitroxides is increased significantly from a few minutes of 3-CP to $6 \mathrm{~h}$; 3) it could provide long-term and significant enhancement in MR imaging of the tumor, liver, kidney and cardiovascular system (heart and aortaventralis), and this is the first report on nitroxides-based MRI CAs for imaging the cardiovascular system.

Conclusions: As a safe and efficient candidate metal-free magnetic resonance contrast agent, Branched pDHPMA-mPEG-Ppa-PROXYL is expected to be used not 
only in tumor, liver and kidney imaging, but also in cardiovascular system imaging, which expands the application scope of this kind of CAs.

Keywords Metal-free contrast agents, nitroxides, magnetic resonance imaging, polymers

\section{Introduction}

Magnetic resonance imaging (MRI) is a very effective medical imaging technology which has been widely used in the clinical diagnosis of many diseases [1-3]. However, conventional MRI examinations often have insufficient image contrast, so MRI contrast agents need to be applied for patients to obtain clearer and more accurate diagnostic results [4-7]. At present, metal-based MRI contrast agents (CAs) are commonly used clinically, including paramagnetic $\mathrm{Gd}^{3+}$ chelate (T1, positive contrast agents) and superparamagnetic $\mathrm{Fe}_{3} \mathrm{O}_{4}$ nanoparticles (T2, negative contrast agents) [8-11]. Unfortunately, both of them have inevitable metal-related toxicity [12-14]. Therefore, it has become a research hotspot to overcome the toxicity of metal-based MRI CAs.

In this process, a concept of non-metallic MRI CAs has emerged. Currently, paramagnetic nitrogen oxide radicals (nitroxides) (such as PROXYL, TEMPO, etc.) are being extensively studied because their good stability and imaging mechanism are similar to metal-based contrast agents (such as $\mathrm{Gd}^{3+}$ chelate-based clinical CAs) [15-19]. However, there are some inherent obstacles of nitroxides that need to be overcame to achieve clinical MRI CAs. First of all, the unpaired electrons (only one) of nitroxides are less than $\mathrm{Gd}(\mathrm{III})$ ions (containing seven), so the $\mathrm{T} 1$ relaxation efficiency $\left(r_{l}\right)$ of nitroxides are significantly lower than that of contrast agents based on $\mathrm{Gd}(\mathrm{III})$ ions. In addition, due to the reducible sensitivity, nitroxides will be quickly converted into non-relaxing nitrohydroxyl compounds by the reductive substances in the body [20-24]. And the result is losing paramagnetism, which leads to their short half-life and cannot provide sufficient window time for MR imaging. Previous researches [25-29] have proven that the construction of macromolecular nitroxides-based contrast agents (mORCAs) is a promising solution via the macromolecularization of nitroxides (ie, large molecules carry nitroxides). 
Macromolecular effect not only improve the stability of nitroxides by limiting their exposure to reductive substances in the body, but also improve the overall ${ }^{1} \mathrm{H}$ water relaxation by increasing the concentration of nitroxides and slowing the molecular rotation speed [27, 30-33]. However, these mORCAs have not obtained ideal results. It mainly faces two problems: (1) the relaxivities and in vivo imaging time need to be further improved; (2) the biosecurity of macromolecular materials needs to be solved. For it, in the early stage, we used linear and cross-linked biodegradable PEGylated polyester to construct two novel mORCAs which have made unprecedented achievements in solving the above two problems, and the cross-linked one was the most outstanding [34]. Although the above studies have not completely solved the problems faced by mORCAs, it has injected great expectation and hope into the research field. Therefore, it is necessary to develop more macromolecular carrier materials for constructing more mORCAs in order to find the ideal metal-free MRI CAs.

Among macromolecular carriers, biodegradable poly[N-(1, 3-dihydroxypropyl) methacrylamide] (DHPMA copolymers) are favored due to their great structure controllability, diversified functions, long-term blood circulation, excellent water solubility, non-immunogenicity and good biosafety [35-39]. These copolymers have been successfully employed for the development of metal-based macromolecular CAs (mCAs) [30, 40, 41]. Therefore, it is expected that the combination of small molecular nitroxide radicals with biodegradable DHPMA copolymers could result in safe and efficient metal-free MRI mCAs. These copolymers help nitroxides to improve the relaxivity in vitro and accumulation of nitroxides in some tissues and organs in vivo, thereby generating a multiplication effect to achieve improvement in the imaging contrast. Meanwhile, these DHPMA copolymers have been demonstrated to display low side effects [42].

In this study, we designed and synthesized a novel nitroxide radicals-based mCA, Branched pDHPMA-mPEG-Ppa-PROXYL, which was derived from an enzyme/GSH sensitive PEGylated branched DHPMA copolymer as the macromolecular skeleton. Amphiphilic Branched pDHPMA-mPEG-Ppa-PROXYL could self-assembly into nano-sized aggregates in an aqueous environment. As shown in Fig. 1, the hydrophilic 
components formed the outer layer to encapsulate hydrophobic nitroxides (PROXYL) inside, thereby enhancing the stability of PROXYL. Enhanced stability combined with the macromolecular effects, including long blood circulation, increased nitroxides concentration and slow molecular rotation, rendered this nitroxides-based metal-free mCA to be used for MR imaging of multiple-target in vivo including tumor, liver, kidney and cardiovascular system (heart and aortaventralis). In particular, to our knowledge, this is the first report on nitroxides-based MRI CAs for imaging the cardiovascular system.

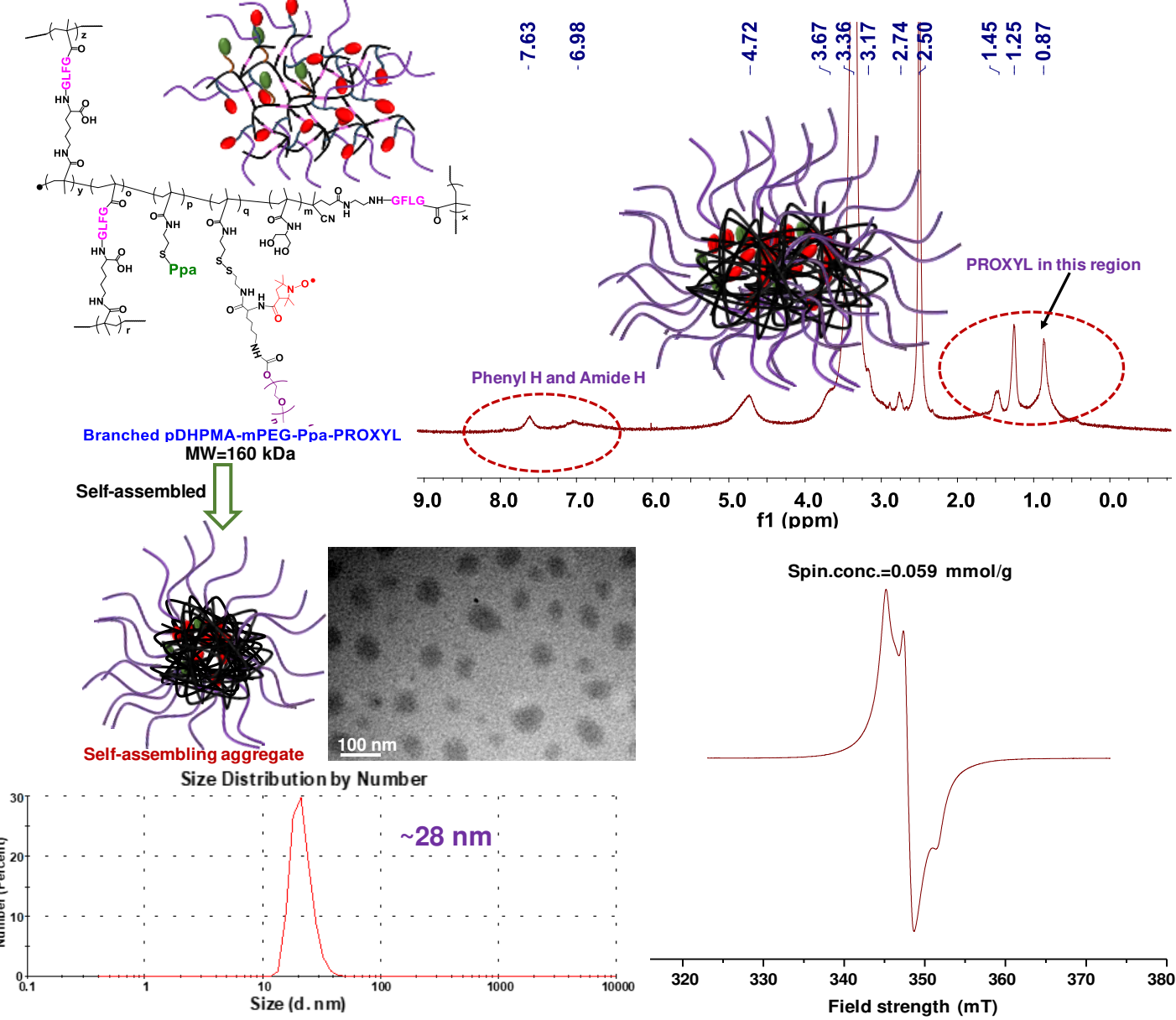

Fig. 1 The structure and self-assembly of Branched pDHPMA-mPEG-Ppa-PROXYL.

\section{Materials and Methods}

Materials, methods, synthesis of the PROXYL-based branched biodegradable mORCA (Branched pDHPMA-mPEG-Ppa-PROXYL, Scheme S1) and its characterizations (Table S1) were put in the Supporting Information. In vitro or vivo 
toxicity, blood compatibility test and cell uptake experiment methods were put in the Supporting Information.

\section{Animal and tumor models}

All animals were fed in a control room. $7 \times 10^{5} 4 \mathrm{~T} 1$ cells were inoculated subcutaneously in the dorsal side of each mouse. When the tumor reached $100 \mathrm{~mm}^{3}$, all experimental mice randomly divided for MR imaging and other experimental studies.

\section{In vitro relaxivity and in vivo MR imaging}

The longitudinal relaxivity of Branched pDHPMA-mPEG-Ppa-PROXYL in phosphate buffer saline (PBS) was measured using a clinical Siemens 3.0 T MRI scanner. Branched pDHPMA-mPEG-Ppa-PROXYL at different concentrations of PROXYL $(0,0.17,0.34,0.68,1.35,2.7,5.4,10.8 \mathrm{mM})$ was dissolved in 0.1 M PBS, and MR signals of the prepared solutions were scanned by T1 SE sequence with scanning parameters: $\mathrm{TE}=8.7 \mathrm{~ms}, \mathrm{TR}=20,30,50,70,90,125,150,175,200,300$, 400, 500, 700, 850, and $1000 \mathrm{~ms}$, Fov $=200 \mathrm{~mm}$, slice thickness $=1.0 \mathrm{~mm}$, and matrix dimensions $=256 \times 256$. The corresponding $1 / \mathrm{T} 1$ values were obtained from their T1-weighted MR images. The value of relaxivity $\left(r_{l}\right)$ was calculated by plotting 1/T1 as a function of different PROXYL concentrations. In addition, 3-Carboxy-PROXYL (3-CP) at the same concentration in 0.1 M PBS was used as a control.

Twenty 8-10 weeks healthy female BALB/c mice were arbitrarily divided into four groups (5 in each group, $20 \pm 2 \mathrm{~g}$ ). Another ten female BALB/c mice of tumor-bearing (20 $\pm 2 \mathrm{~g}, 8$-10 weeks) were also arbitrarily divided into two groups (n = 5). The MR signals of main organs (heart, liver and kidney), aortaventralis and tumor in the body at different time points were obtained via a clinical Siemens 3.0 T MRI scanner. A mouse coil was employed, and the $\mathrm{T}_{1}$ mapping sequence was used for coronal scanning. The scan sequence was: $\mathrm{TR}=15 \mathrm{~ms}, \mathrm{TE}=2.04 \mathrm{~ms}$, flip angle $=$ $5^{\circ} / 26^{\circ}$, slices $=10$, thickness $=2.0 \mathrm{~mm}$, and Fov $=156 \times 156 \mathrm{~mm}$. Scanning was executed at pre-injection, 5, 10, 15, 20, 25, and $30 \mathrm{~min}$ after injection to obtain images of each organ, and the METALAB software [43] was used to analyze the $\mathrm{T}_{1}$ values of 
each organ and aortaventralis before and after enhancement.

\section{In vivo metabolism}

Ten female healthy BALB/c mice (8-10 weeks, $20 \pm 2 \mathrm{~g}$ ) were randomly divided into two groups $(\mathrm{n}=5)$, and Branched pDHPMA-mPEG-Ppa-PROXYL and 3-CP were injected through the tail vein at a dose of $0.135 \mathrm{mmol} / \mathrm{kg}$ PROXYL, respectively. 50 $\mu \mathrm{L}$ of blood samples were collected through the fundus vein at time points of $3 \mathrm{~min}, 6$ $\min , 9 \mathrm{~min}, 12 \mathrm{~min}, 15 \mathrm{~min}, 30 \mathrm{~min}, 1 \mathrm{~h}, 2 \mathrm{~h}, 4 \mathrm{~h}, 8 \mathrm{~h}$, and $24 \mathrm{~h}$ after injection. The blood samples were centrifuged $(10000 \mathrm{~g} \times 5 \mathrm{~min})$ and the serum supernatants were collected. The spin concentration (the nitroxides content) of each serum sample at different time points was measured by electronic paramagnetic resonance (EPR).

\section{Results and discussion}

\section{Preparation and characterization of Branched pDHPMA-mPEG-Ppa-PROXYL}

According to our previous studies, Gd(III)-based mCAs constructed from DHPMA copolymers with branched structure generally could make full use of the macromolecular effect to achieve high relaxivities and good in vivo MR imaging. Therefore, in this study, we prepared a branched DHPMA copolymer whose each branched chain contains an enzyme sensitive GFLG peptide for the construction of a novel biodegradable Branched PROXYL-based mORCA (Branched PCE-mPEG-Ppa-PROXYL, as shown in Scheme S1) in the hope of effectively improving the relaxivity and in vivo MR imaging of PROXYL via significant macromolecular effect. In addition, the detail characterization is listed in Table S1.

Firstly, we prepared a PEGylated PROXYL derivative functionalized by dithiopyridyl (PTE) (PTE-mPEG-PROXYL, as shown in Scheme S1) the way we did before [34], and PTE-mPEG-PROXYL has the following functions: 1) the PTE groups can reacted with thiols (thiol-disulfide exchange reaction) to covalently introduce PROXYL derivatives onto macromolecular material, forming the corresponding mORCA; 2) Due to strong hydrophobility of PROXYL, its introduction will weaken the water solubility of the mORCA, so we adopted PEGylation to solve this problem, in addition, PTE-mPEG-PROXYL contains the same amount of $\mathrm{mPEG}_{2000}$ and 
PROXYL, so after covalently connecting with the macromolecule, it can achieve a good water-solubility and obtain a higher content of PROXYL, so as to ensure the full play of the multiplier effect; 3) Additionally, PEGylation can further improve MW of the mORCA and enhance its biocompatibility and in vivo stability.

On the other hand, in our previous study, a branched DHPMA copolymer with short enzyme-sensitive GFLG peptide in each branch chain (Branched pDHPMA-SH, as shown in Scheme S1) was prepared via RAFT polymerization induced by VA044 of DHPMA, PTEMA, MA-GFLGK-MA and MA-GFLG-NH-CTA. And the Gd-based mCA derived from this copolymer displayed excellent relaxation performance both in vivo and in vitro, and also good biodegradability and low side effects [42]. Inspired by this result, we selected Branched pDHPMA-SH as macromolecular carrier to construct a novel PROXYL-based mORCA (Branched pDHPMA-mPEG-Ppa-PROXYL, as shown in Scheme S1). The synthesis process was two steps: (1) First, the maleimide-functionalized pyropheophorbide- $\alpha$ (Ppa-Maleimide) as the fluorescent probe was covalently introduced via thiol-ene click chemistry, and the input quantity of Ppa-Maleimide did not exceed 1\% of the total amount of raw material, which can not only meet the requirements of fluorescence imaging but also not affect the water solubility of the final copolymer; (2) Next, the PEGylated PROXYL derivative was covalently introduced via disulfide-thiol exchange reaction. The structure of the final copolymer was confirmed by ${ }^{1} \mathrm{HNMR}$ (Fig. S1), and gel permeation chromatography (GPC) measured its MW as $160 \mathrm{kDa}$ (Table S1). EPR analysis showed that the copolymer had paramagnetism and the spin concentration (nitroxides content) was $0.059 \mathrm{mmol} / \mathrm{g}$ (Fig. S2). According to our design ideas, Branched pDHPMA-mPEG-Ppa-PROXYL has amphipathy and can self-assemble into an aggregate with a certain nanometer-size in water phase. For verifying this, we analyzed the particle size and morphology of the copolymer by dynamic light scattering (DLS) and transmission electron microscopy (TEM), and the results showed that Branched pDHPMA-mPEG-Ppa-PROXYL could form a self-assembling aggregate with $28 \mathrm{~nm}$ of particle size (Fig. S3-4). The amino acid analysis result (Table S2) showed that the molar ratio of Gly/Phe/Leu was ca. 1.4/1.7/1, which 
indicated that the short peptide GFLG was introduced into the mORCA. Additionally, from DLS (Fig. S5), the zeta potential of the final copolymer was ca. $0 \mathrm{mV}$, which indicated that the surface of Branched pDHPMA-mPEG-Ppa-PROXYL was electrically neutral, so it can prevent its adsorption by proteins in the blood, resulting in long retention time in the blood.

\section{Relaxivity of Branched pDHPMA-mPEG-Ppa-PROXYL}

A clinical Siemens 3.0 T MRI scanner was used to measure the longitudinal relaxivity $\left(r_{1}\right)$ of Branched pDHPMA-mPEG-Ppa-PROXYL with 3-CP as a control. Bright signals were seen from the Branched pDHPMA-mPEG-Ppa-PROXYL samples in MRI images, and these signals were more intense than those from 3-CP at the equivalent PROXYL concentration (Fig. 2a). As shown in Fig. 2b, the $r_{l}$ values were calculated by plotting 1/T1 with the gradient concentration of Branched pDHPMA-mPEG-Ppa-PROXYL and 3-CP. The in vitro relaxation efficiency $\left(r_{1}=\right.$ $0.50 \mathrm{mM}^{-1} \mathrm{~s}^{-1}$ ) of Branched pDHPMA-mPEG-Ppa-PROXYL was significantly higher than that $\left(r_{l}=0.17 \mathrm{mM}^{-1} \mathrm{~s}^{-1}\right)$ of 3-CP.

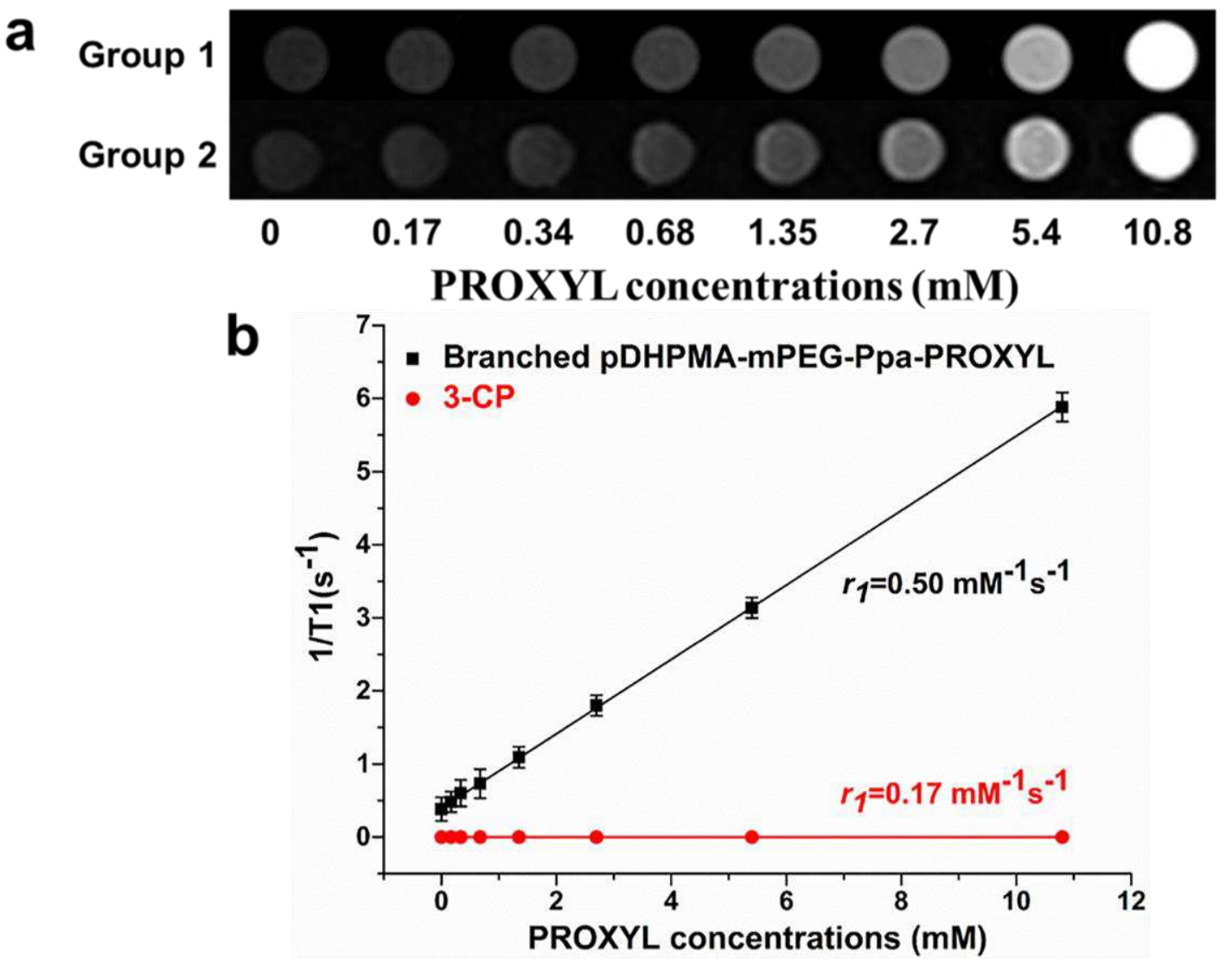

Fig. 2 a MRI signals and $\mathbf{b}$ in vitro longitudinal relaxivity $\left(r_{1}\right)$ of Branched 
pDHPMA-mPEG-Ppa-PROXYL (Group 1) and 3-CP (Group 2).

\section{In vivo major organ and aortaventralis imaging}

A clinical 3T MRI scanner was used to detect MRI signals of Branched pDHPMA-mPEG-Ppa-PROXYL in living mice to evaluate its suitability as an MRI CA. A small molecule, 3-CP, was employed as a control. As shown in Fig. 3a, the signals in the heart were intensified significantly at $5 \mathrm{~min}$ after injection, and the intensified trend continued to reach a peak at $15 \mathrm{~min}$. After that, the signals became slowly weakened, while bright signals were still detectable at 30 min after injection of the contrast agent. Additionally, MR signals in the aortaventralis appeared to be strengthened during the initial 5 min after injection and the signal peak was reached at $5 \mathrm{~min}$. The degree of signal enhancement started to decrease after $5 \mathrm{~min}$, and at 30 min the signal intensity (SI) was observed to reduce to the same level as that before injection (Fig. 3b). In the liver (Fig. 4a), the MRI SI began to increase and reached the enhancement peak at $5 \mathrm{~min}$ after injection. After $5 \mathrm{~min}$, the SI began to decline continuously, and recovered at the pre-injection level in $30 \mathrm{~min}$. The SI appeared to increase in the kidney (Fig. 4b) after 5 min and it reached an enhancement peak at 10 min. The enhancement was noticed to last until 25 min after injection of the mCA, and the MRI SI returned to the pre-injection level at about $30 \mathrm{~min}$.

Furthermore, we performed quantitative analysis of MRI images in the heart, liver, kidney and aortaventralis via the $\mathrm{T}_{1}$ value. In the heart (Fig. $3 \mathrm{c}$ ), the $\mathrm{T}_{1}$ value increased in the initial few minutes after injection of the $\mathrm{mCA}$ and reached the enhancement peak at 15 min. An increase by about $168 \%$ in the $\mathrm{T}_{1}$ value was achieved in comparison with the level before enhancement (Fig. 3e). After 15 min, the $T_{1}$ value gradually decreased. The increasing pattern was also seen for the $T_{1}$ value in the aortaventralis (Fig. 3d), while the change gradient was much steeper and the value peaked at 5 min with an increase by about $120 \%$ compared to the level before enhancement (Fig. 3e). In the liver (Fig. 4c), the $\mathrm{T}_{1}$ value increased significantly within 5 min post-injection of the $\mathrm{mCA}$ and peaked at $5 \mathrm{~min}$ with the same trend as the MRI SI. The $\mathrm{T}_{1}$ value was enhanced by about $137 \%$ compared to the level before enhancement (Fig. 4e). The $\mathrm{T}_{1}$ value then gradually decreased and reduced to the 
pre-injection level at $30 \mathrm{~min}$. In the kidney (Fig. $4 \mathrm{~d}$ ), the $\mathrm{T}_{1}$ value increased to a peak at $10 \mathrm{~min}$ with an enhancement of about $136 \%$ compared to the level before enhancement (Fig. 4e). Both MRI SI and the $\mathrm{T}_{1}$ value in the organs (heart, liver and kidney) and aortaventralis displayed negligible changes after injection of 3-CP (Fig. S6-S8). This can be explained as: (1) Branched pDHPMA-mPEG-Ppa-PROXYL has higher relaxation efficiency in vitro; (2) Branched pDHPMA-mPEG-Ppa-PROXYL can form self-assembled aggregates with a larger particle size in the aqueous environment, and the hydrophobic nitroxides are encapsulated in the hydrophobic interior of the self-assembled aggregates, so it can provide relatively long and stable MRI enhancement in the heart, liver, kidney and aortaventralis. At the same time, the MRI SI and $T_{1}$ value of the kidney increased, suggesting that Branched pDHPMA-mPEG-Ppa-PROXYL is mainly metabolized by the kidney, thereby ensuring its safety.

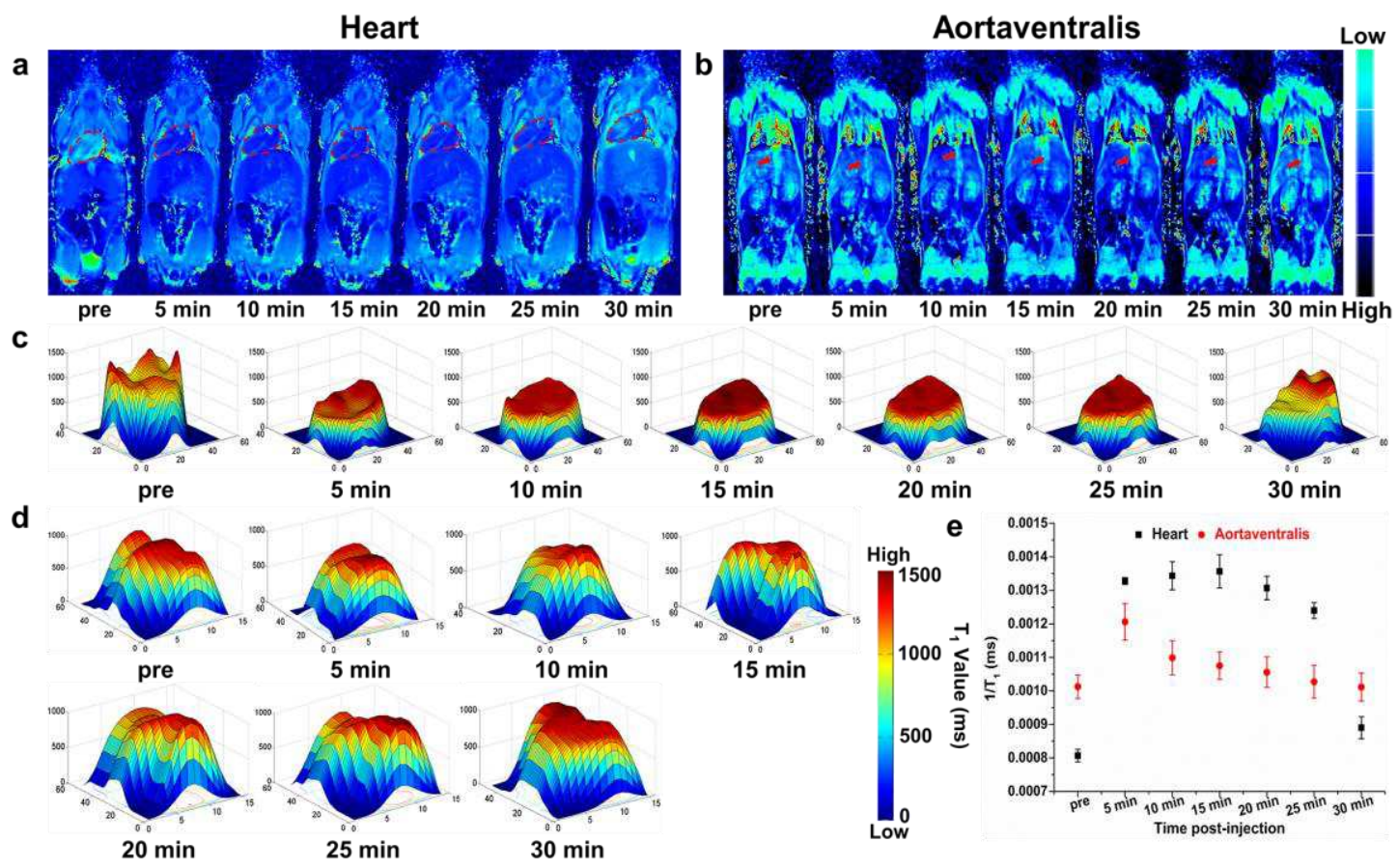

Fig. $3 \mathrm{~T}_{1}$ mapping imaging of heart $\mathbf{a}$ and aortaventralis $\mathbf{b}$ after injection of Branched pDHPMA-mPEG-Ppa-PROXYL. The heart and aortaventralis were labeled with red dashed lines and red arrow, respectively. The darker blue signals in the heart and aortaventralis suggest sharper enhancement in the MR images. The corresponding $T_{1}$ values were spatially displayed in the heart c and aortaventralis $\mathbf{d}$ after injection of Branched pDHPMA-mPEG-Ppa-PROXYL at different 
durations. e The $1 / T_{1}$ values for the heart and aortaventralis were quantitatively analyzed $(\mathrm{p}<$ $0.05)$.
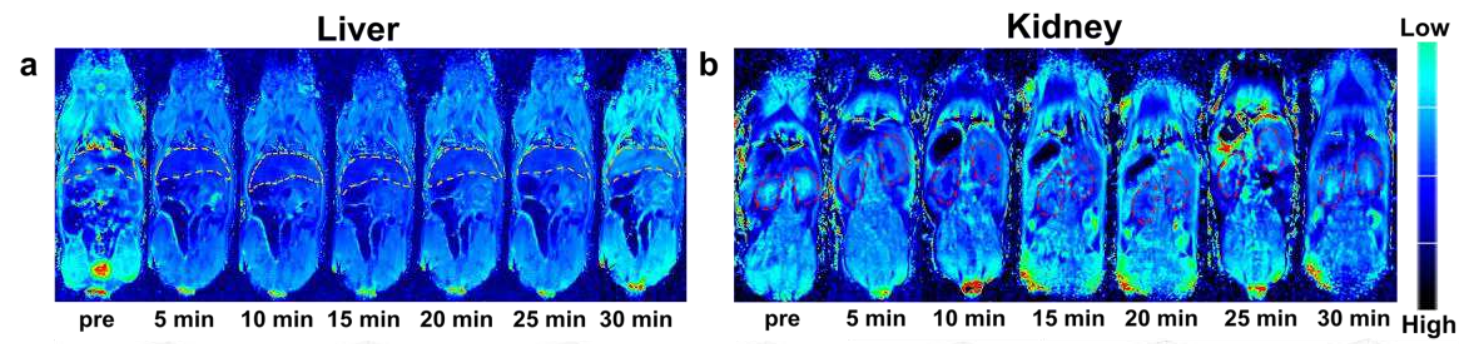

$$
\text { C }
$$
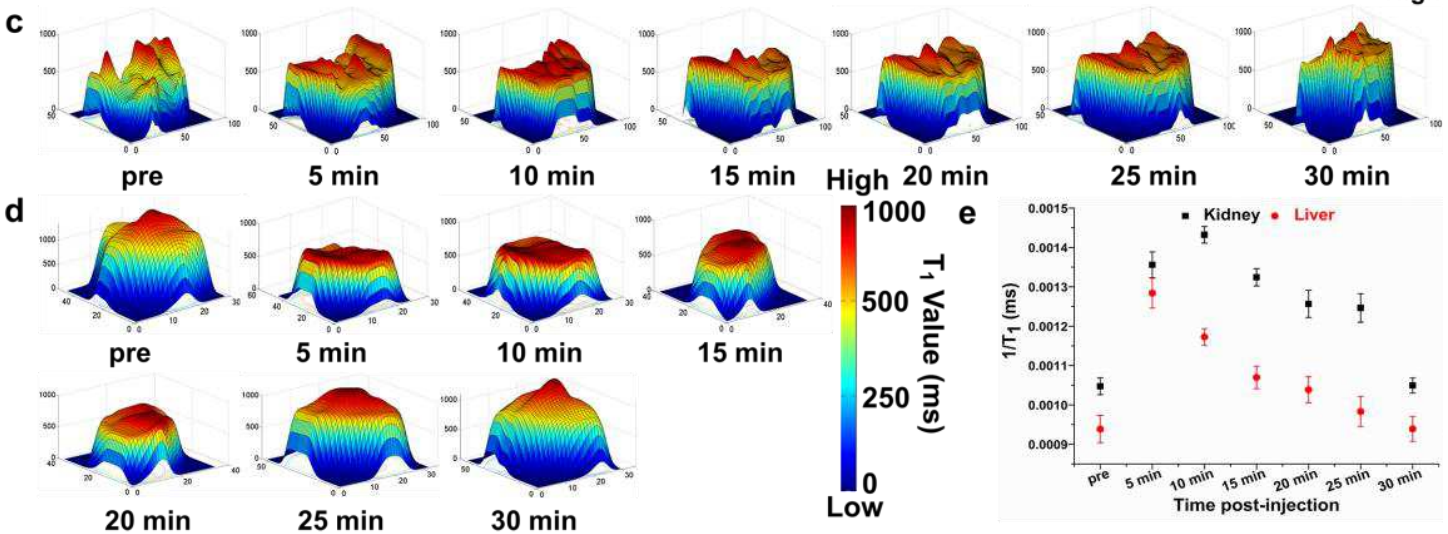

Fig. $4 \mathrm{~T}_{1}$ mapping imaging of liver $\mathbf{a}$ and kidney $\mathbf{b}$ after injection of Branched pDHPMA-mPEG-Ppa-PROXYL. The liver and kidney were labeled with yellow and red dashed lines, respectively. The darker blue signals in the liver and kidney suggest sharper enhancement in the MR images. The corresponding $T_{1}$ values were spatially displayed in the liver $\mathbf{c}$ and kidney $\mathbf{d}$ after injection of Branched pDHPMA-mPEG-Ppa-PROXYL at different durations. e The $1 / \mathrm{T}_{1}$ values for the liver and kidney were quantitatively analyzed $(\mathrm{p}<0.05)$.

\section{In vivo tumor imaging}

Based on the above good in vitro and in vivo MR imaging, we further studied the imaging efficacy of Branched pDHPMA-mPEG-Ppa-PROXYL at the tumor site. We also used $T_{1}$ mapping sequences to scan and observe the MRI enhancement of tumor-bearing mice at various time points. The imaging efficacy was quantified by $\mathrm{T}_{1}$ value, and 3-CP was also set up as a control group for the same scan.

After the injection of the contrast agents, the MRI signal at the tumor site began to strengthen within 5 minutes and reached the enhancement peak (Fig. 5a), and then began to decrease continuously, returning to the pre-injection level at 30 minutes. Quantitative analysis of the above tumor MRI images by $\mathrm{T}_{1}$ value (Fig. $5 \mathrm{~b}$ ) shows that Branched pDHPMA-mPEG-Ppa-PROXYL reached the enhancement peak of the 
tumor site at ca. 5 minutes. The $\mathrm{T}_{1}$ value increased by about $144 \%$ (Fig. 5c), showing a very high enhancement effect, this result was also consistent with the in vitro relaxivity results. After 5 minutes, the $\mathrm{T}_{1}$ value gradually decreased and returned to the pre-injection level at ca. 30 minutes. Subsequently, small molecular 3-CP group was scanned by the same method as described above, and no significant increase in the signal at the tumor site was found (Fig. S9). It is known that tumor tissue contains higher concentrations of reducing substances (such as GSH) than normal tissues, and this will seriously affect the MR imaging efficacy of Branched pDHPMA-mPEG-Ppa-PROXYL in tumor, but the passive target ability to tumor and the protection of PROXYL by the amphiphilic structure still allowed Branched pDHPMA-mPEG-Ppa-PROXYL to provide good MRI enhancement in tumor tissue.

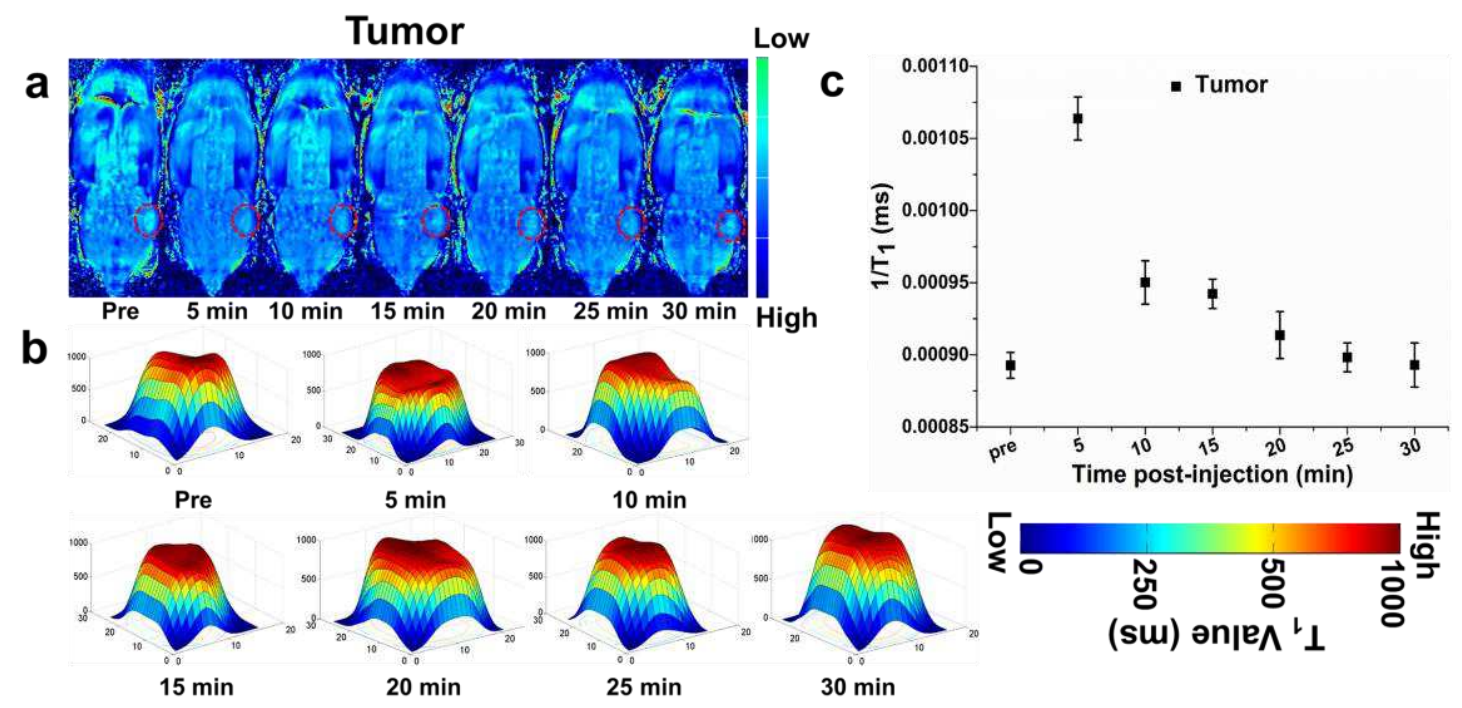

Fig. $5 \mathrm{~T}_{1}$ mapping imaging of tumor by Branched pDHPMA-mPEG-Ppa-PROXYL a. The tumor was labeled with red lines, and darker blue signals in the tumor suggest sharper enhancement in the MR images. The corresponding $T_{1}$ values were spatially displayed in the tumor after injection of Branched pDHPMA-mPEG-Ppa-PROXYL $\mathbf{b}$ at different durations. $\mathbf{c}$ The $1 / \mathrm{T}_{1}$ values of two tumor groups were quantitatively analyzed $(\mathrm{p}<0.05)$.

\section{In vivo metabolism of PROXYL}

To measure the residence time of nitroxides induced from Branched pDHPMA-mPEG-Ppa-PROXYL in the blood, we injected Branched pDHPMA-mPEG-Ppa-PROXYL and 3-CP as a control into normal mice via tail vein at a dose of $0.135 \mathrm{mmol}$ PROXYL/kg, and the blood samples at the same volume 
were collected at different pre-established time points to analyze the nitroxides concentrations in these blood samples by EPR.

The temporal changes of nitroxides concentrations in the blood of mice were shown in Fig. 6. It was observed that the PROXYL concentrations of 3-CP in the blood rapidly decreased and they were below the detection limit at $1 \mathrm{~h}$ after the injection, indicating that the small molecule, 3-CP, was rapidly eliminated by reducing substances in the blood. However, the PROXYL concentration reduced much slowly in the Branched pDHPMA-mPEG-Ppa-PROXYL group. In the initial post-injection period, the nitroxides concentration was high. Although the PROXYL concentration in the Branched pDHPMA-mPEG-Ppa-PROXYL group displayed a similar decreasing trend as that in the 3-CP group, the reduction rate of the nitroxides concentration in the Branched pDHPMA-mPEG-Ppa-PROXYL group was much less steep than that in the 3-CP group, and the nitroxides were still detectable until $6 \mathrm{~h}$ after injection.

The macromolecular structure of Branched pDHPMA-mPEG-Ppa-PROXYL plays a critical role in the extended circulation time of nitroxides: (1) The nitroxides are protected in the hydrophobic core of self-assembled aggregates, which results in a decrease in the interaction rate between endogenous reducing substances in the blood and nitroxides, thereby, nitroxides residues are still detectable up to $6 \mathrm{~h}$ post-injection; (2) As a macromolecule, Branched pDHPMA-mPEG-Ppa-PROXYL itself has a long blood retention time. A long blood retention time of Branched pDHPMA-mPEG-Ppa-PROXYL allows great accumulation of this mCA in the major organ, aortaventralis and tumor tissues, thus, enhanced imaging contrast in these places are achieved. 


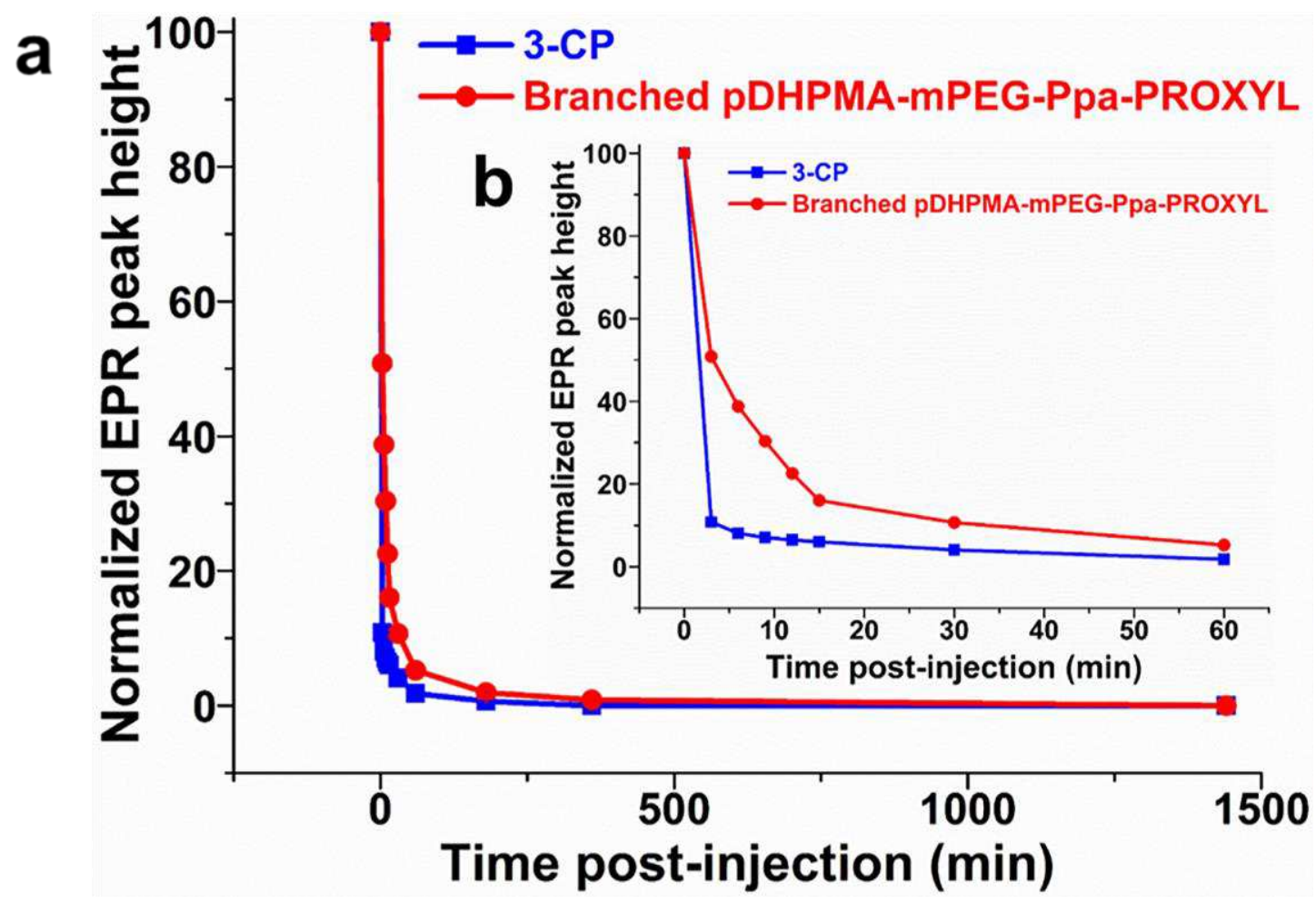

Fig. 6 a Nitroxides concentration distribution in vivo for $24 \mathrm{~h}$ after injection of Branched pDHPMA-mPEG-Ppa-PROXYL and 3-CP and $\mathbf{b}$ nitroxides concentration changes within $1 \mathrm{~h}$.

\section{Cellular uptake}

CLSM was used to study the uptake behavior and distribution of Branched pDHPMA-mPEG-Ppa-PROXYL in 4T1 cells. It was observed that Branched pDHPMA-mPEG-Ppa-PROXYL started to enter 4T1 cells at 1 hour after incubation, and the cytoplasmic fluorescence intensity at 6 hours after incubation was significantly stronger than the 1 and 2 hours after incubation. Branched pDHPMA-mPEG-Ppa-PROXYL accumulated completely in the cytoplasm (red fluorescence) and did not enter the nucleus (blue fluorescence) (Fig. 7). The experimental results showed that Branched pDHPMA-mPEG-Ppa-PROXYL could be taken up by 4T1 cells and completely distributed in the cytoplasm without entering the nucleus, and the cells have a time-dependent behavior for the cellular uptake of this mORCA. 


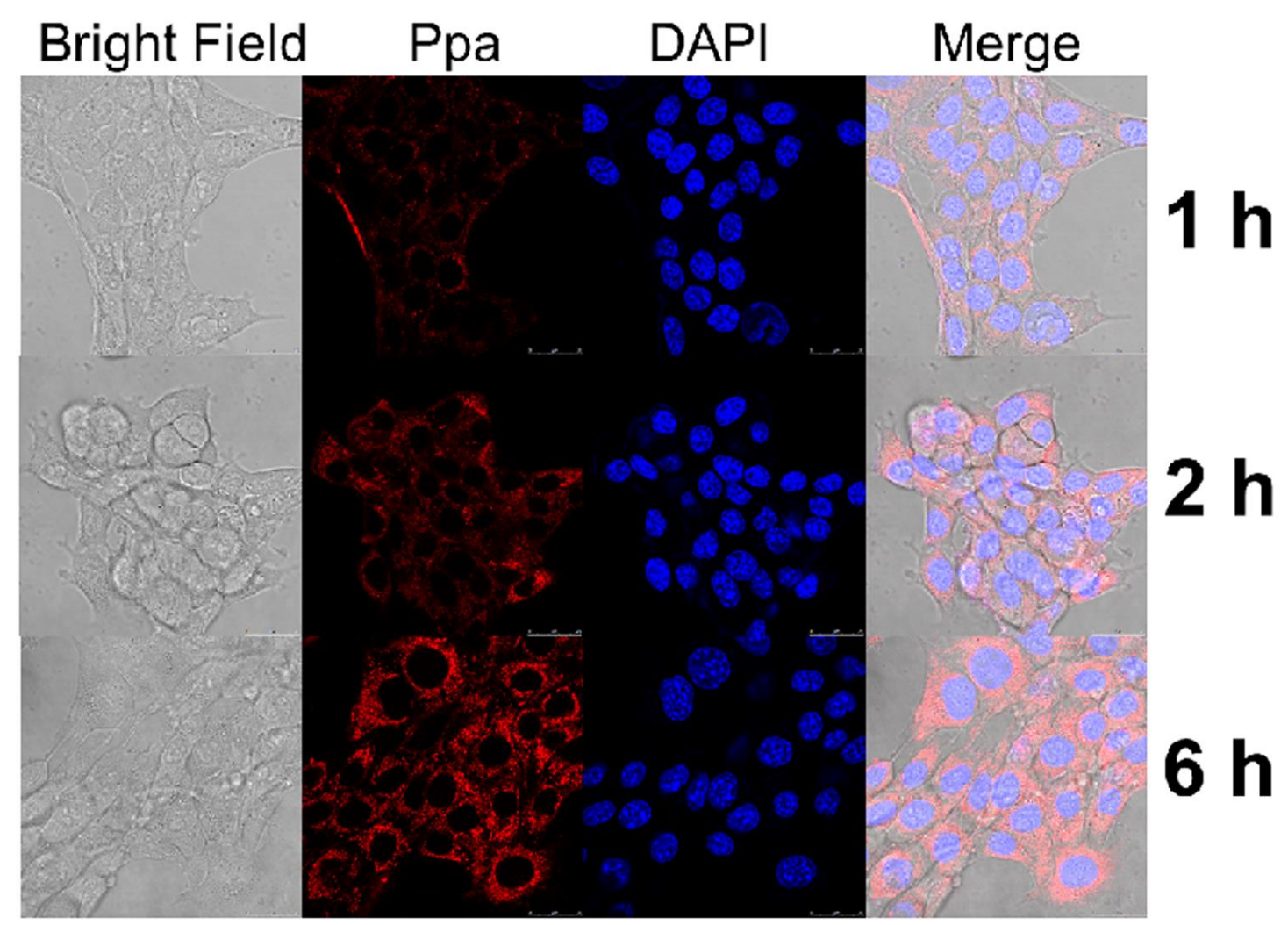

Fig. 7 CLSM images of Branched pDHPMA-mPEG-Ppa-PROXYL incubated with 4T1 cells for 1 h, $2 \mathrm{~h}$, and $6 \mathrm{~h}$.

\section{In vitro cyotoxicty}

As shown in Fig. 8a, after incubation with Branched pDHPMAmPEG-Ppa-PROXYL (from 0 to $1 \mathrm{mg} / \mathrm{mL}$ ) for $24 \mathrm{~h}$, the viability of 4T1 and HUVEC cells showed no significant difference, and the concentration of PROXYL had negligible impact on the cell viability, which indicated that Branched pDHPMA-mPEG-Ppa PROXYL had no obvious toxicity to 4T1 and HUVEC cells. This could be due to a neutral surface charge of Branched pDHPMA-mPEG-Ppa PROXYL and a biodegradable macromolecular structure since short peptide linker GFLG in the structure could be cleaved by cathepsin B in the body.

\section{Blood compatibility evaluation}

We observed the RBC morphology to evaluate hemolysis induced by Branched pDHPMA-mPEG-Ppa-PROXYL. The morphology of RBCs was observed via SEM to evaluate the biological safety of Branched pDHPMA-mPEG-Ppa-PROXYL. As shown in Fig. 8b, after Branched pDHPMA-mPEG-Ppa-PROXYL at different 
concentrations were incubated with RBCs, the morphology of RBCs did not change significantly, and no red blood cells were aggregated. At a high magnification (1000x), the membrane surface of RBCs was smooth and intact with a normal biconcave disk-like structure. Compared with the PBS control group, there were no obvious changes with any abnormal structures such as collapse and rupture. Therefore, Branched pDHPMA-mPEG-Ppa-PROXYL did not cause any changes in the morphology and aggregation of RBCs and they had great biological safety.

After adding Branched pDHPMA-mPEG-Ppa-PROXYL to the whole blood, we measured the hemolysis with pure water and PBS as controls. The results showed that Branched pDHPMA-mPEG-Ppa-PROXYL did not cause hemolytic reaction at each concentration (Fig. 8c), which indicated that Branched pDHPMA-mPEG-Ppa-PROXYL had great blood compatibility and reliable biological safety. The degree of hemolysis is often quantified with the amount of hemoglobin released from red blood cells after they are ruptured. The microplate reader was used to measure the absorbance of the sample at $540 \mathrm{~nm}$ because the absorption wavelength of hemoglobin is at $540 \mathrm{~nm}$ and the hemoglobin content in the samples can be determined from the absorbance. The ASTM standards suggest that the hemolysis level for blood compatibility should be less than 5\%. After we incubated Branched pDHPMA-mPEG-Ppa-PROXYL at 1.0, 2.0, and $5.0 \mathrm{mg} / \mathrm{mL}$ for $12 \mathrm{~h}$, the hemolysis level at each concentration of the mCA was less than 5\% (Fig. 8d), and no significant difference was observed compared with PBS. Therefore, Branched pDHPMA-mPEG-Ppa-PROXYL had excellent blood compatibility.

\section{In vivo toxicity evaluation}

In order to evaluate the biological safety of Branched pDHPMA-mPEG-Ppa-PROXYL as a safe MR contrast agent, three groups of normal mice $(\mathrm{n}=5)$ were injected with Branched pDHPMA-mPEG-Ppa-PROXYL, 3-CP (dose of $0.135 \mathrm{mmol} / \mathrm{kg}$ PROXYL) and saline via tail vein, respectively. After $24 \mathrm{~h}$ of injection, the mice did not display obvious acute toxic and side effects (such as bleeding, motor ataxia, death, etc.). The mice were killed and main organs (heart, liver, spleen, lung and kidney) were dissected for pathological analysis. The analysis results 
(Fig. 8e) showed that compared with the 3-CP and saline control groups, no obvious tissue damage and histopathological abnormalities (such as inflammation, necrosis, atrophy, atrophy, tissue deformation, etc.) were seen in the mCA group. The experimental results indicated that at the MR imaging dose, Branched pDHPMA-mPEG-Ppa-PROXYL was non-toxic to the organs and tissues of living animals.

a

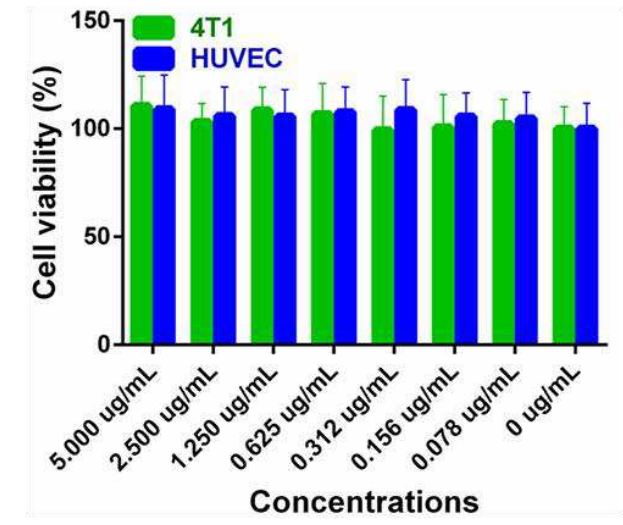

C
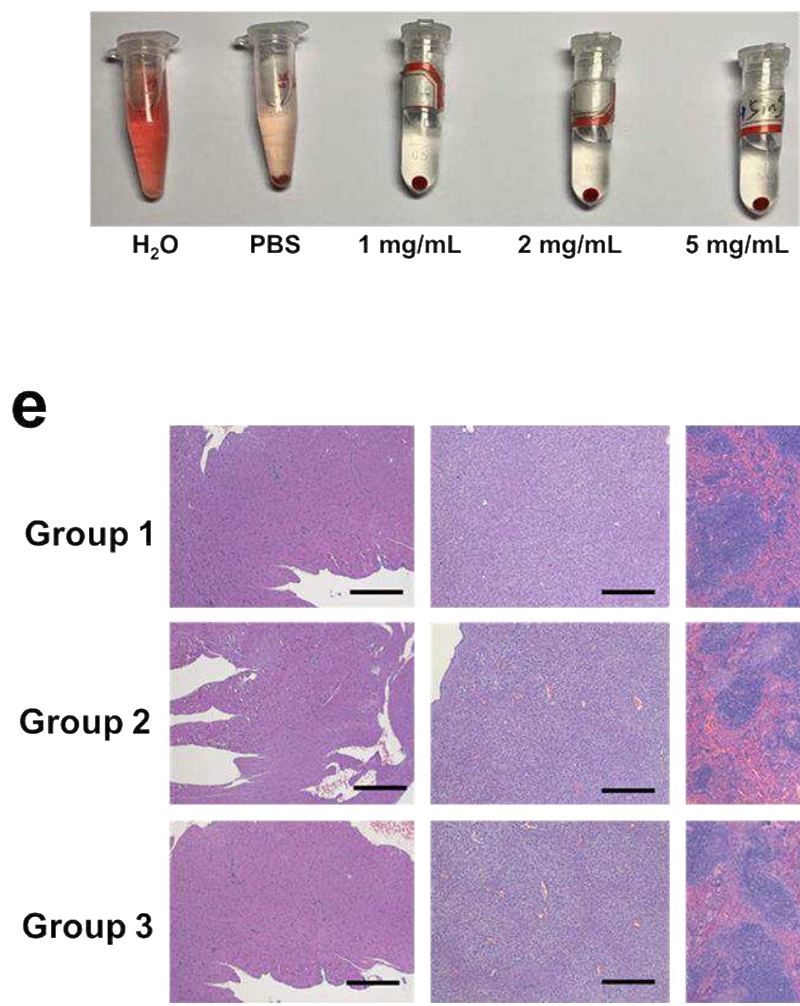

b
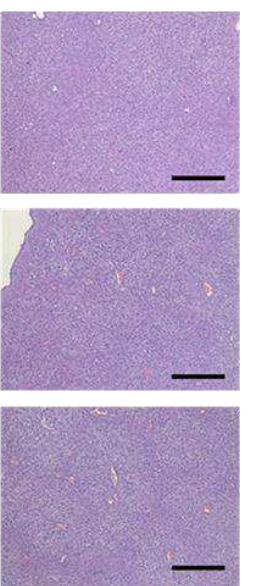
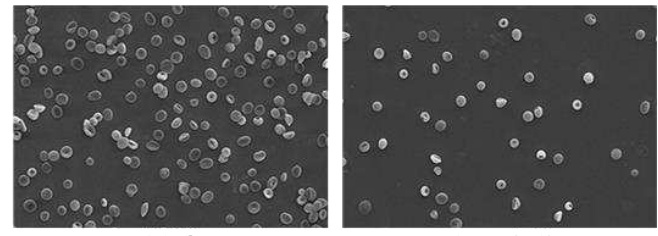

PBS

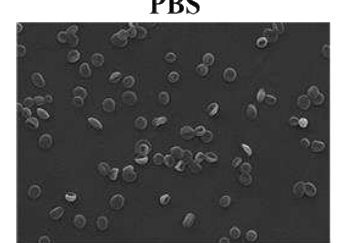

$2 \mathrm{mg} / \mathrm{mL}$

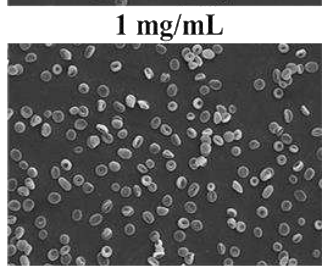

$5 \mathrm{mg} / \mathrm{mL}$

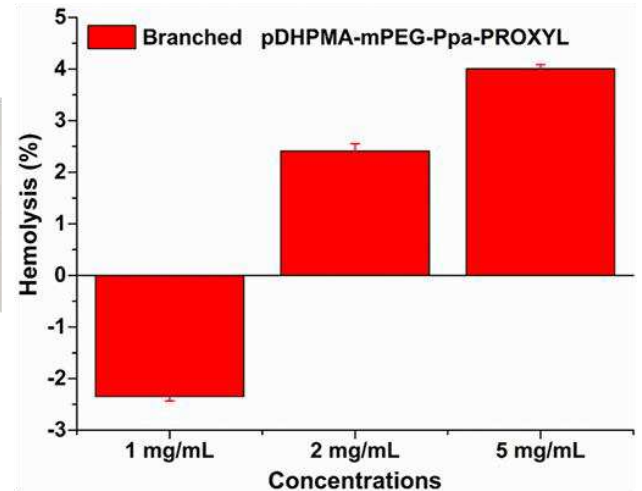

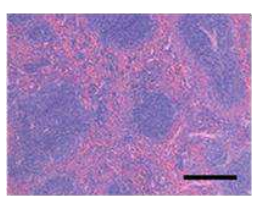
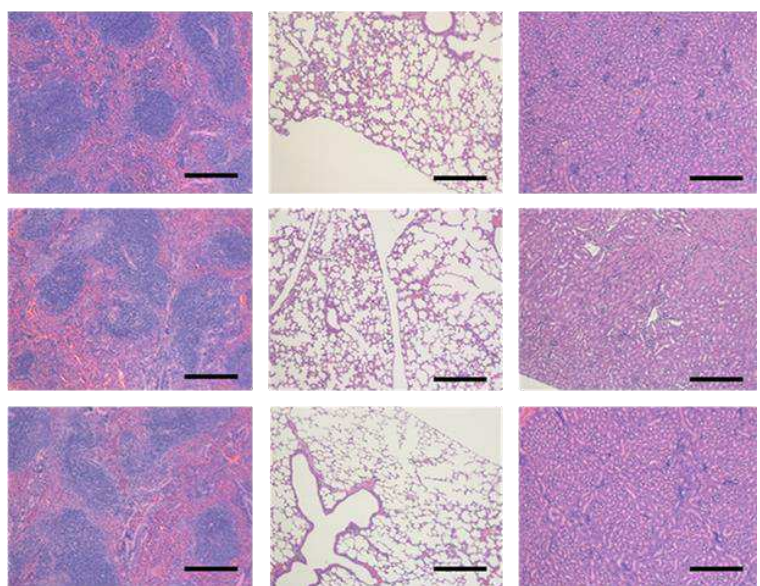
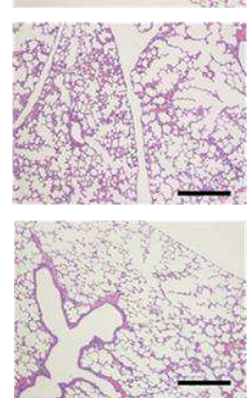

Fig. 8 a Cell viability of $4 \mathrm{~T} 1$ cells and HUVEC cells after incubating with Branched pDHPMA-mPEG-Ppa-PROXYL for $24 \mathrm{~h}$. b The effects of PBS, $1 \mathrm{mg} / \mathrm{mL}, 2 \mathrm{mg} / \mathrm{mL}$, and 5mg/mL Branched pDHPMA-mPEG-Ppa-PROXYL on erythrocyte aggregation and morphology. $\mathbf{c}$ Red 
blood cell hemolysis of Branched pDHPMA-mPEG-Ppa-PROXYL. d Hemolysis rates of Branched pDHPMA-mPEG-Ppa-PROXYL at different concentrations. e Histological images of mice 1 day after injection of saline (Group 1), 3-CP (Group 2) and Branched pDHPMA-mPEG-Ppa-PROXYL (Group 3). Scale bar: $10 \mu \mathrm{m}$.

\section{Conclusion}

Herein, we designed and prepared a water-soluble biodegradable branched polymeric nitroxides as a novel metal-free mCA (Branched pDHPMA-mPEG-Ppa-PROXYL) via covalently conjugation of a PEGylated PROXYL derivative onto an enzyme sensitive degradable branched pDHPMA. Its molecular weight (MW) and nitroxide radical content are $160 \mathrm{kDa}$ and $0.059 \mathrm{mmol} / \mathrm{g}$, respectively. Addtionally, it is amphiphilic and can form a nanoscale $(\sim 28 \mathrm{~nm})$ self-assembled aggregate in a physiological environment, which is beneficial to: prolong the circulation time in vivo; enhance the targeting of specific tissues (e.g. tumor); reduce the contact between PROXYL in hydrophobic core and reducing substances in vivo thus enhancing its stability. Thanks to the macromolecular effects and the higher nitroxides content, in vivo and in vitro studies showed that Branched pDHPMA-mPEG-Ppa-PROXYL was superior to small molecular 3-CP in many aspects including the in vitro longitudinal relaxivity, the in vivo stability of PROXYL and MR imaging efficacy. At the same time, it did not show obvious toxicity in vivo. It should be pointed out that compared with the all CAs of the same kind reported previously, Branched pDHPMA-mPEG-Ppa-PROXYL could not only work in tumor and some major organs (e.g. liver and kidney), but also provide MR imaging enhancement in cardiovascular system. Therefore, Branched pDHPMA-mPEG-Ppa-PROXYL has the potential to be a safe and efficient metal-free mCA for multi-object MRI in vivo.

\section{Abbreviations}

MRI: magnetic resonance imaging; CAs: contrast agents; mCA: macromolecular contrast agent; 3-CP: 3-Carboxy-2,2,5,5-tetramethylpyrrolidine-1-oxyl; pDHPMA: N-(1,3-dihydroxypropyl) methacrylamide copolymer; GSH: glutathione; PEG: polyethylene glycol; Ppa: polyphthalamide; PBS: phosphate buffer saline; TE: echo time; TR: repetition time; Fov: field of view; EPR: electronic paramagnetic resonance; SI: signal intensity; CCK8: Cell Counting Kit-8; CLSM: confocal laser scanning microscope; MW: molecular weight; GFLG: Gly-Phe-Leu-Gly; PROXYL: 2, 2, 5, 5-tetramethylpyrrolidine-1-oxyl; TEMPO: 2, 2, 6, 6-tetramethylpiperidine-1-oxide. 


\section{Acknowledgements}

Not applicable.

\section{Authors' contributions}

XM W, SW G, KL: conception and design of the experiment, as well as manuscript writing; QL, YD: collection an assembly of data and data interpretation; HZ: edit the manuscript, support and discussions; XM W, SW G: perform the experiment; KL, ZQ L: technical and financial support; QY G: conception and design, financial support and the preparation. All authors read and approved the final manuscript.

\section{Funding}

This study was supported by the National Natural Science Foundation of China (51873120, 51673127, 81621003), the Open Project Program of Nuclear Medicine and Molecular Imaging Key Laboratory of Sichuan Province (HYX20006), the base and cutting-edge research projects of Chongqing Science and Technology Bureau (cstc2019jcyj-msxmX0116), China Postdoctoral Foundation Project (2020TQ0212), Doctoral Research Startup Fund of the Affiliated Hospital of Southwest Medical University (19067), University level research fund of Southwest Medical University (2019ZQN026).

\section{Availability of data and materials}

All data generated or analyzed during this study are included in this published article and its Additional file 1.

\section{Ethics approval and consent to participate}

All animal experiments are conducted after obtaining ethical approval from the Institutional Animal Ethics Committee of the Sichuan University, Chengdu (No. 2018148A and 2018150A).

\section{Consent for publication}

All authors agree to be published.

\section{Competing interest}

There are no conflicts to declare.

\section{References}

1. Lin SP, Brown JJ. MR contrast agents: physical and pharmacologic basics. J Magn Reson Imaging. 2007;25:884-899.

2. Barandov A, Bartelle BB, Williamson CG, Loucks ES, Lippard SJ, Jasanoff A. Sensing intracellular calcium ions using a manganese-based MRI contrast agent. Nat Commun. 2019;10:897. 
3. Pellico J, Ellis CM, Davis JJ. Nanoparticle-Based Paramagnetic Contrast Agents for Magnetic Resonance Imaging. Contrast Media Mol Imaging. 2019; 2019:1845637.

4. Gao Z, Ma T, Zhao E, Docter D, Yang W, Stauber RH, Gao M. Small is Smarter: Nano MRI Contrast Agents - Advantages and Recent Achievements. Small. 2016;12:556-576.

5. Fu S, Cai Z, Ai H. Stimulus-Responsive Nanoparticle Magnetic Resonance Imaging Contrast Agents: Design Considerations and Applications. Adv Healthc Mater. 2020:e2001091.

6. Nguyen TDT, Marasini R, Rayamajhi S, Aparicio C, Biller D, Aryal S. Erythrocyte membrane concealed paramagnetic polymeric nanoparticle for contrast-enhanced magnetic resonance imaging. Nanoscale. 2020;12:4137-4149.

7. Cheng CA, Chen W, Zhang L, Wu HH, Zink JI. Magnetic resonance imaging of high-intensity focused ultrasound-stimulated drug release from a self-reporting core@shell nanoparticle platform. Chem Commun (Camb). 2020;56:10297-10300.

8. Wahsner J, Gale EM, Rodríguez-Rodríguez A, Caravan P. Chemistry of MRI Contrast Agents: Current Challenges and New Frontiers. Chem Rev. 2019;119:957-1057.

9. Cao Y, Xu L, Kuang Y, Xiong D, Pei R. Gadolinium-based nanoscale MRI contrast agents for tumor imaging. J Mater Chem B. 2017;5:3431-3461.

10. Israel LL, Galstyan A, Holler E, Ljubimova JY. Magnetic iron oxide nanoparticles for imaging, targeting and treatment of primary and metastatic tumors of the brain. J Control Release. 2020;320:45-62.

11. Zhang W, Liu L, Chen H, Hu K, Delahunty I, Gao S, Xie J. Surface impact on nanoparticle-based magnetic resonance imaging contrast agents. Theranostics. 2018;8:2521-2548.

12. Hatje V, Bruland KW, Flegal AR. Increases in Anthropogenic Gadolinium Anomalies and Rare Earth Element Concentrations in San Francisco Bay over a 20 Year Record. Environ Sci Technol. 2016;50:4159-4168.

13. Fretellier N, Granottier A, Rasschaert M, Grindel AL, Baudimont F, Robert P, Idée JM, Corot C. Does Age Interfere With Gadolinium Toxicity and Presence in Brain and Bone Tissues?: A Comparative Gadoterate Versus Gadodiamide Study in Juvenile and Adult Rats. Invest Radiol. 2019;54:61-71.

14. Qu Y, Li Y, Liao S, Sun J, Li M, Wang D, Xia C, Luo Q, Hu J, Luo K, Gong Q, Song B. Linear and Core-Crosslinked Glycopolymer-Gadolinium Conjugates: Preparation and Their Behaviors as Nanoscale Magnetic Resonance Imaging Contrast Agents. J Biomed Nanotechnol. 2019;15:1637-1653.

15. Nguyen HV, Chen Q, Paletta JT, Harvey P, Jiang Y, Zhang H, Boska MD, Ottaviani MF, Jasanoff A, Rajca A, Johnson JA. Nitroxide-Based Macromolecular Contrast Agents with Unprecedented Transverse Relaxivity and Stability for Magnetic Resonance Imaging of Tumors. ACS Cent Sci. 2017;3:800-811.

16. Jungmann PM, Agten CA, Pfirrmann CW, Sutter R. Advances in MRI around metal. J Magn Reson Imaging. 2017;46:972-991.

17. Mauri E, Micotti E, Rossetti A, Melone L, Papa S, Azzolini G, Rimondo S, Veglianese P, Punta C, Rossi F, Sacchetti A. Microwave-assisted synthesis of TEMPO-labeled hydrogels traceable with MRI. Soft Matter. 2018;14:558-565.

18. Celani A. Tempo is the key. Elife. 2020;9.

19. Lazarova D, Shibata S, Ishii I, Zlateva G, Zhelev Z, Aoki I, Higashi T, Bakalova R. 
Nitroxide-enhanced magnetic resonance imaging of kidney dysfunction in vivo based on redox-imbalance and oxidative stress. Gen Physiol Biophys. 2019;38:191-204.

20. Wang Y, Paletta JT, Berg K, Reinhart E, Rajca S, Rajca A. Synthesis of unnatural amino acids functionalized with sterically shielded pyrroline nitroxides. Org Lett. 2014;16:5298-5300.

21. Soikkeli M, Sievanen K, Peltonen J, Kaasalainen T, Timonen M, Heinonen P, Ronkko S, Lehto VP, Kavakka JS, Heikkinen S. Synthesis and in vitro phantom NMR and MRI studies of fully organic free radicals, TEEPO-glucose and TEMPO-glucose, potential contrast agents for MRI. Rsc Advances. 2015;5:15507-15510.

22. Dobrynin S, Kutseikin S, Morozov D, Krumkacheva O, Spitsyna A, Gatilov Y, Silnikov V, Angelovski G, Bowman MK, Kirilyuk I, Chubarov A. Human Serum Albumin Labelled with Sterically-Hindered Nitroxides as Potential MRI Contrast Agents. Molecules. 2020;25.

23. Soikkeli M, Kettunen MI, Nivajärvi R, Olsson V, Rönkkö S, Laakkonen JP, Lehto VP, Kavakka J, Heikkinen S. Assessment of the Relaxation-Enhancing Properties of a Nitroxide-Based Contrast Agent TEEPO-Glc with In Vivo Magnetic Resonance Imaging. Contrast Media Mol Imaging. 2019;2019:5629597.

24. Akakuru OU, Iqbal MZ, Saeed M, Liu C, Paunesku T, Woloschak G, Hosmane NS, Wu A. The Transition from Metal-Based to Metal-Free Contrast Agents for T(1) Magnetic Resonance Imaging Enhancement. Bioconjug Chem. 2019;30:2264-2286.

25. Rajca A, Wang Y, Boska M, Paletta JT, Olankitwanit A, Swanson MA, Mitchell DG, Eaton SS, Eaton GR, Rajca S. Organic radical contrast agents for magnetic resonance imaging. J Am Chem Soc. 2012;134:15724-15727.

26. Garmendia S, Mantione D, Alonso-de Castro S, Jehanno C, Lezama L, Hedrick JL, Mecerreyes D, Salassa L, Sardon H. Polyurethane based organic macromolecular contrast agents (PU-ORCAs) for magnetic resonance imaging. Polymer Chemistry. 2017;8:2693-2701.

27. Chan JMW, Wojtecki RJ, Sardon H, Lee ALZ, Smith CE, Shkumatov A, Gao S, Kong H, Yang YY, Hedrick JL. Self-Assembled, Biodegradable Magnetic Resonance Imaging Agents: Organic Radical-Functionalized Diblock Copolymers. Acs Macro Letters. 2017;6:176-180.

28. Nguyen HV, Detappe A, Gallagher NM, Zhang H, Harvey P, Yan C, Mathieu C, Golder MR, Jiang Y, Ottaviani MF, A Jasanoff, A Rajca, I Ghobrial, PP Ghoroghchian, JA Johnson. Triply Loaded Nitroxide Brush-Arm Star Polymers Enable Metal-Free Millimetric Tumor Detection by Magnetic Resonance Imaging. ACS Nano. 2018;12:11343-11354.

29. Soikkeli M, Horkka K, Moilanen JO, Timonen M, Kavakka J, Heikkinen S. Synthesis, Stability and Relaxivity of TEEPO-Met: An Organic Radical as a Potential Tumour Targeting Contrast Agent for Magnetic Resonance Imaging. Molecules 2018, 23.

30. Guo S, Xiao X, Wang X, Luo Q, Zhu H, Zhang H, Li H, Gong Q, Luo K. Reductive microenvironment responsive gadolinium-based polymers as potential safe MRI contrast agents. Biomater Sci. 2019;7:1919-1932.

31. Luo Q, Xiao X, Dai X, Duan Z, Pan D, Zhu H, Li X, Sun L, Luo K, Gong Q. Cross-Linked and Biodegradable Polymeric System as a Safe Magnetic Resonance Imaging Contrast Agent. ACS Appl Mater Interfaces. 2018;10:1575-1588.

32. Li H, Meade TJ. Molecular Magnetic Resonance Imaging with Gd(III)-Based Contrast Agents: Challenges and Key Advances. J Am Chem Soc. 2019;141:17025-17041.

33. Czeyda-Pommersheim F, Martin DR, Costello JR, Kalb B. Contrast Agents for MR Imaging. Magn Reson Imaging Clin N Am. 2017;25:705-711. 
34. Guo S, Wang X, Dai Y, Dai X, Li Z, Luo Q, Zheng X, Gu Z, Zhang H, Gong Q, Luo K. Enhancing the Efficacy of Metal-Free MRI Contrast Agents via Conjugating Nitroxides onto PEGylated Cross-Linked Poly(Carboxylate Ester). Adv Sci (Weinh). 2020;7:2000467.

35. Chen K, Cai H, Zhang H, Zhu H, Gu Z, Gong Q, Luo K. Stimuli-responsive polymer-doxorubicin conjugate: Antitumor mechanism and potential as nano-prodrug. Acta Biomater. 2019;84:339-355.

36. Dai Y, Ma X, Zhang Y, Chen K, Tang JZ, Gong Q, Luo K. A biocompatible and cathepsin B sensitive nanoscale system of dendritic polyHPMA-gemcitabine prodrug enhances antitumor activity markedly. Biomater Sci. 2018;6:2976-2986.

37. Wu Y, Zhang W, Li T, Ma R, Chen D, Zhang J, Wu J, Tang J. Multivalent methionine-functionalized biocompatible block copolymers for targeted small interfering RNA delivery and subsequent reversal effect on adriamycin resistance in human breast cancer cell line MCF-7/ADR. J Gene Med. 2017;19.

38. Su F, Agarwal S, Pan T, Qiao Y, Zhang L, Shi Z, Kong X, Day K, Chen M, Meldrum D, VD Kodibagkar, Tian Y. Multifunctional PHPMA-Derived Polymer for Ratiometric pH Sensing, Fluorescence Imaging, and Magnetic Resonance Imaging. ACS Appl Mater Interfaces. 2018;10:1556-1565.

39. Dai Y, Cai H, Duan Z, Ma X, Gong Q, Luo K, Gu Z. Effect of Polymer Side Chains on Drug Delivery Properties for Cancer Therapy. J Biomed Nanotechnol. 2017;13:1369-1385.

40. Zhang Q, Wang S, Qiao R, Whittaker MR, Quinn JF, Davis TP, Li H. Recent Advances in Magnetic Nanoparticle-based Molecular Probes for Hepatocellular Carcinoma Diagnosis and Therapy. Curr Pharm Des. 2018;24:2432-2437.

41. Zu G, Kuang Y, Dong J, Cao Y, Zhang T, Liu M, Luo L, Pei R. Gadolinium(III)-based Polymeric Magnetic Resonance Imaging Agents for Tumor Imaging. Curr Med Chem. 2018;25:2910-2937.

42. Wang X, Guo S, Li Z, Xiao X, Gu L, Luo Q, Zhang H, Gong Q, Luo K. Safe and potent MRI contrast agents by complexing gadolinium with enzyme/reduction dual-sensitive Branched polymers. Appl Mater Today. 2019;17:92-103.

43. Laurent D, Wasvary J, O'Byrne E, Rudin M: In vivo qualitative assessments of articular cartilage in the rabbit knee with high-resolution MRI at 3 T. Magn Reson Med. 2003, 50:541-549. 


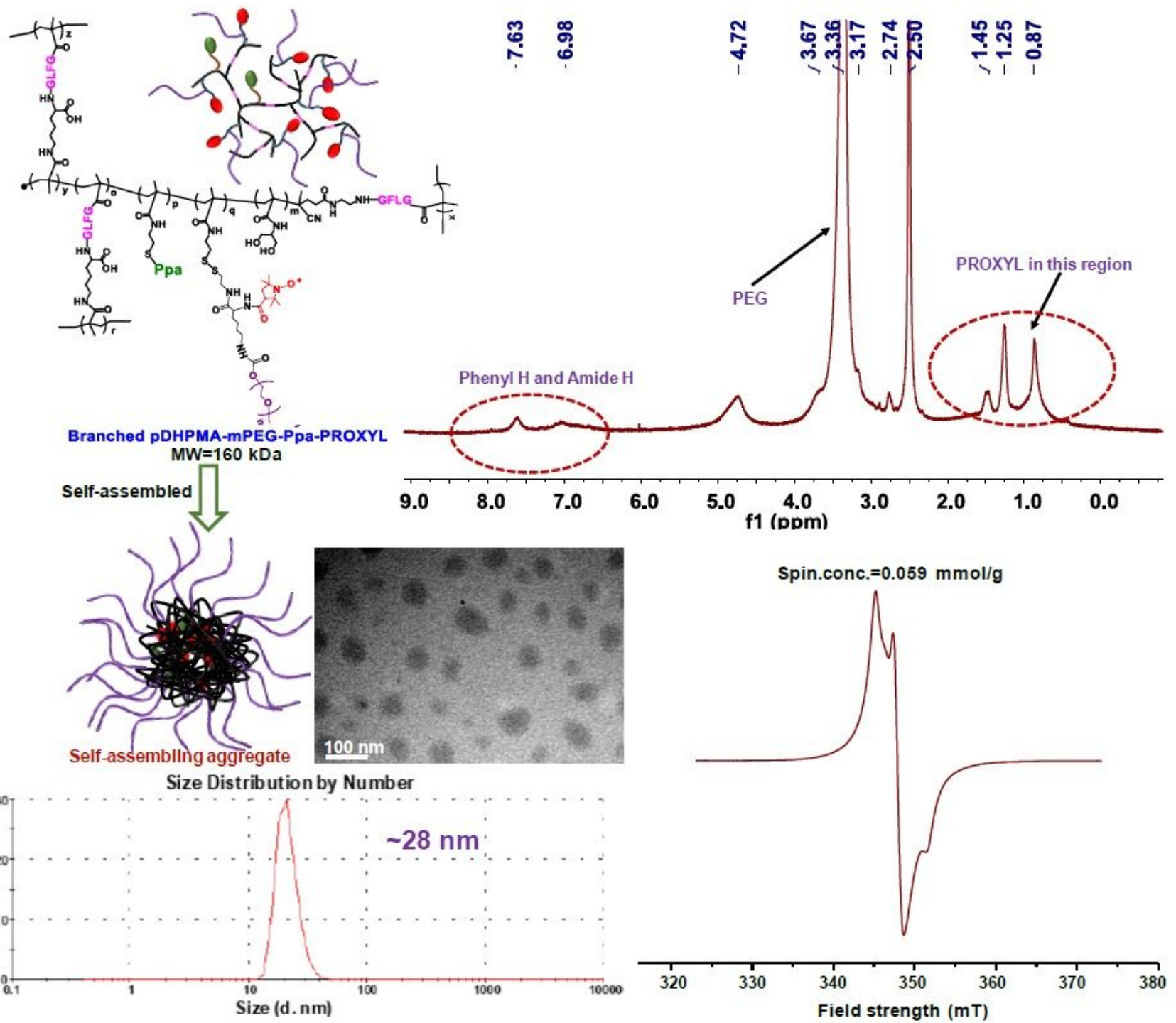

Figure 1

The structure and self-assembly of Branched pDHPMA-mPEG-Ppa-PROXYL. 
a Group 1

Group 2
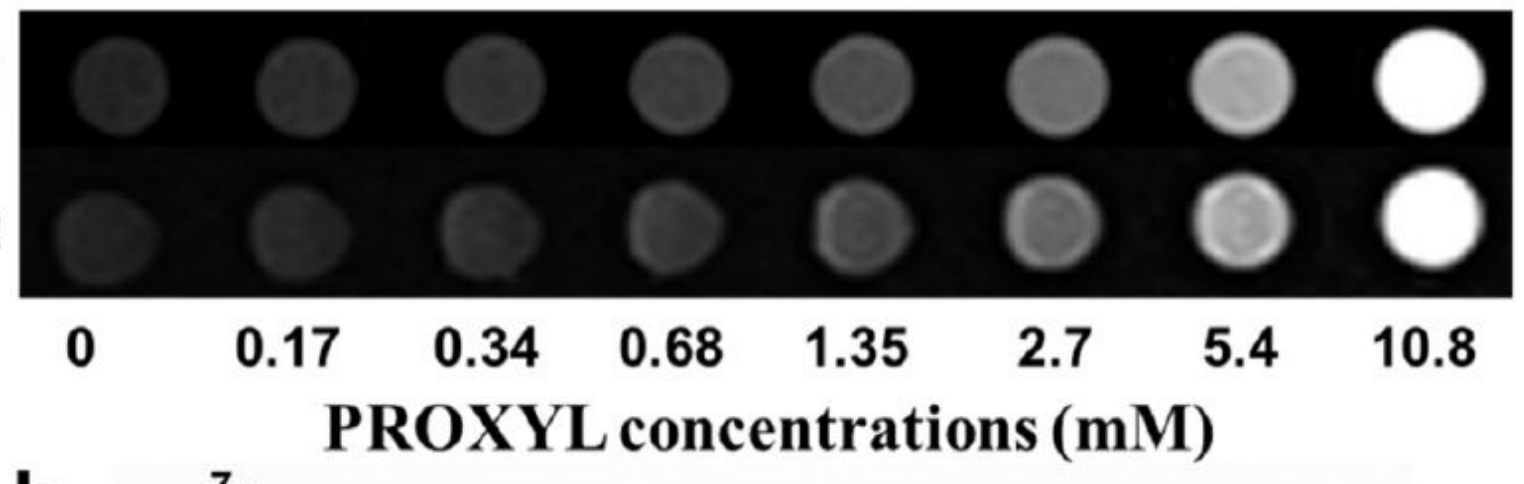

b

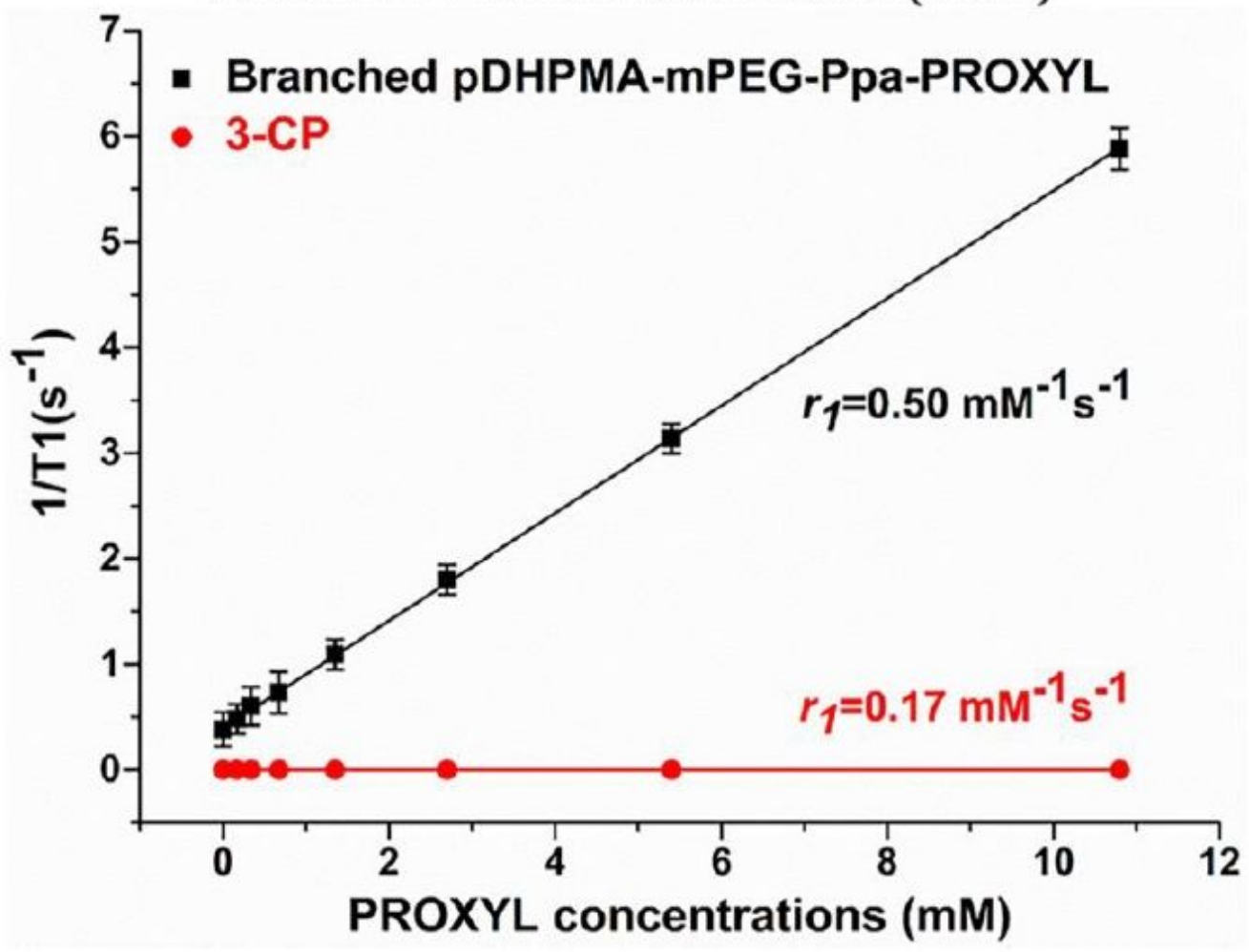

Figure 2

a MRI signals and $b$ in vitro longitudinal relaxivity $(r 1)$ of Branched pDHPMA pDHPMA-mPEGmPEGPpaPpa-PROXYL (Group 1) and 3PROXYL (Group 1) and 3-CP (Group 2).CP (Group 2). 
Heart

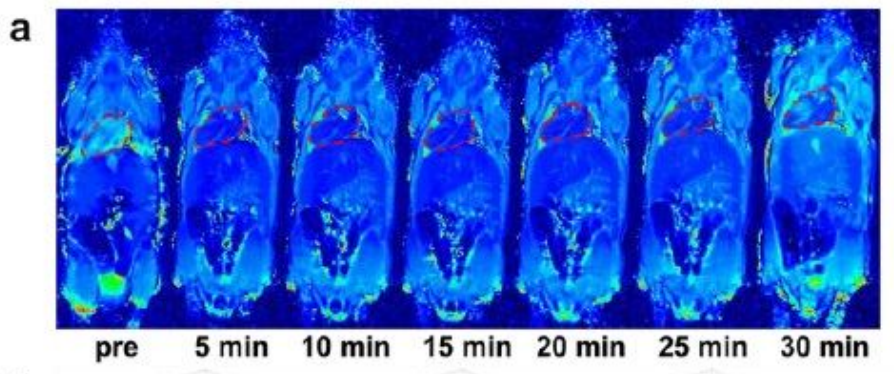

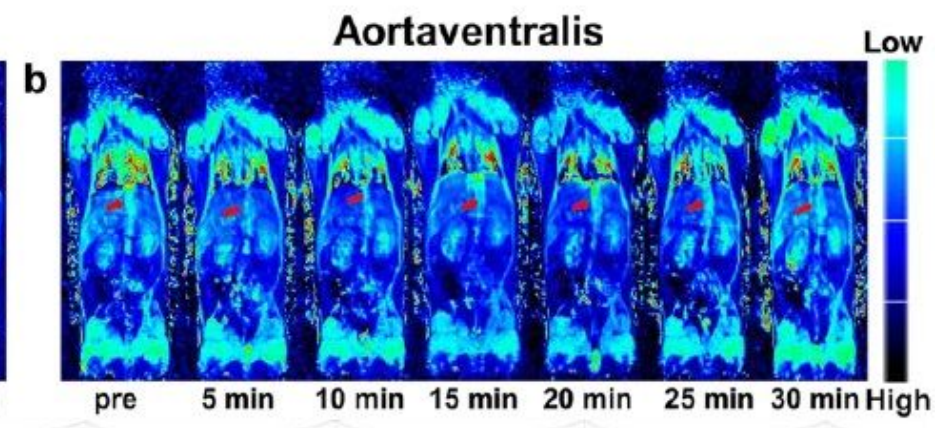

C

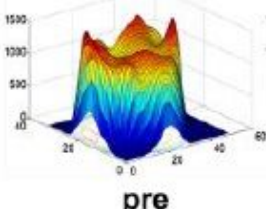

d
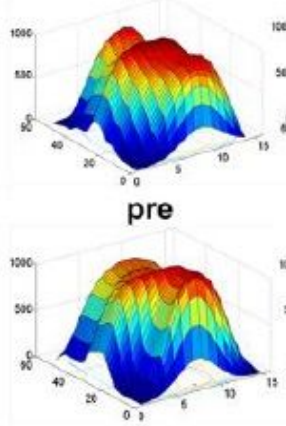

$20 \mathrm{~min}$

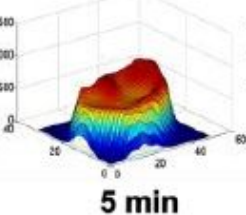

5 min

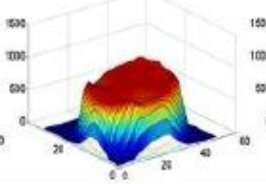

$10 \mathrm{~min}$

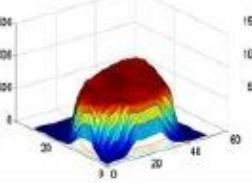

$15 \mathrm{~min}$

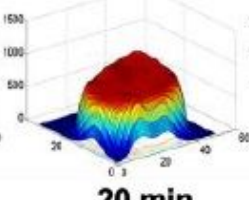

20 min

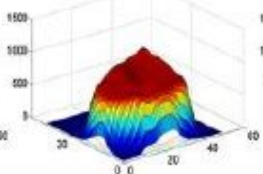

25 min

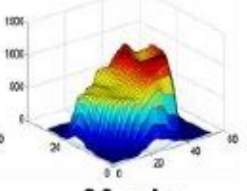

$30 \mathrm{~min}$
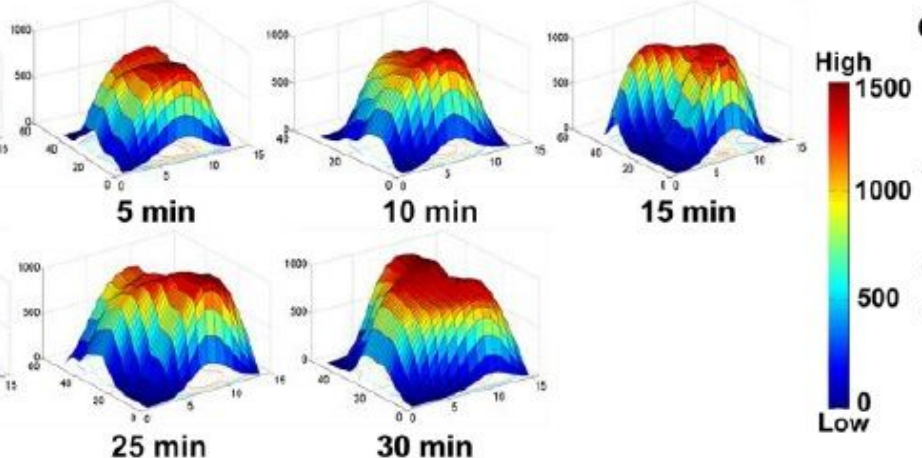

e $\quad 0.0015$

0.0015

- Heart - Aortaventralis

0.0013
0.0012 I I I I

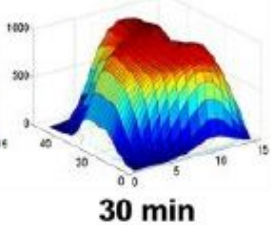

$25 \mathrm{~min}$

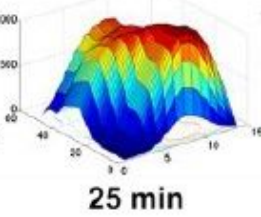

$30 \mathrm{~min}$

\section{Figure 3}

T 1 mapping imaging of heart $a$ and aortaventralis $b$ after injection of Branched pDHPMA mPEG Ppa PROXYL. The heart and aortaventralis were labeled with red dashed lines and red arrow, respectively. The darker blue signals in the heart and aortaventralis suggest sharper enhancement in the MR images. The corresponding $\mathrm{T} 1$ values were sp atially displayed in the heart $\mathrm{c}$ and aortaventralis $\mathrm{d}$ after injection of Branched pDHPMA mPEG Ppa PROXYL at different durations. durations. ee The 1/TThe 1/T11 values for the heart and aortaventralis were quantitatively analyzevalues for the heart and aortaventralis were quantitatively analyzed $(p<d(p<0.05) \cdot 0.05)$. 


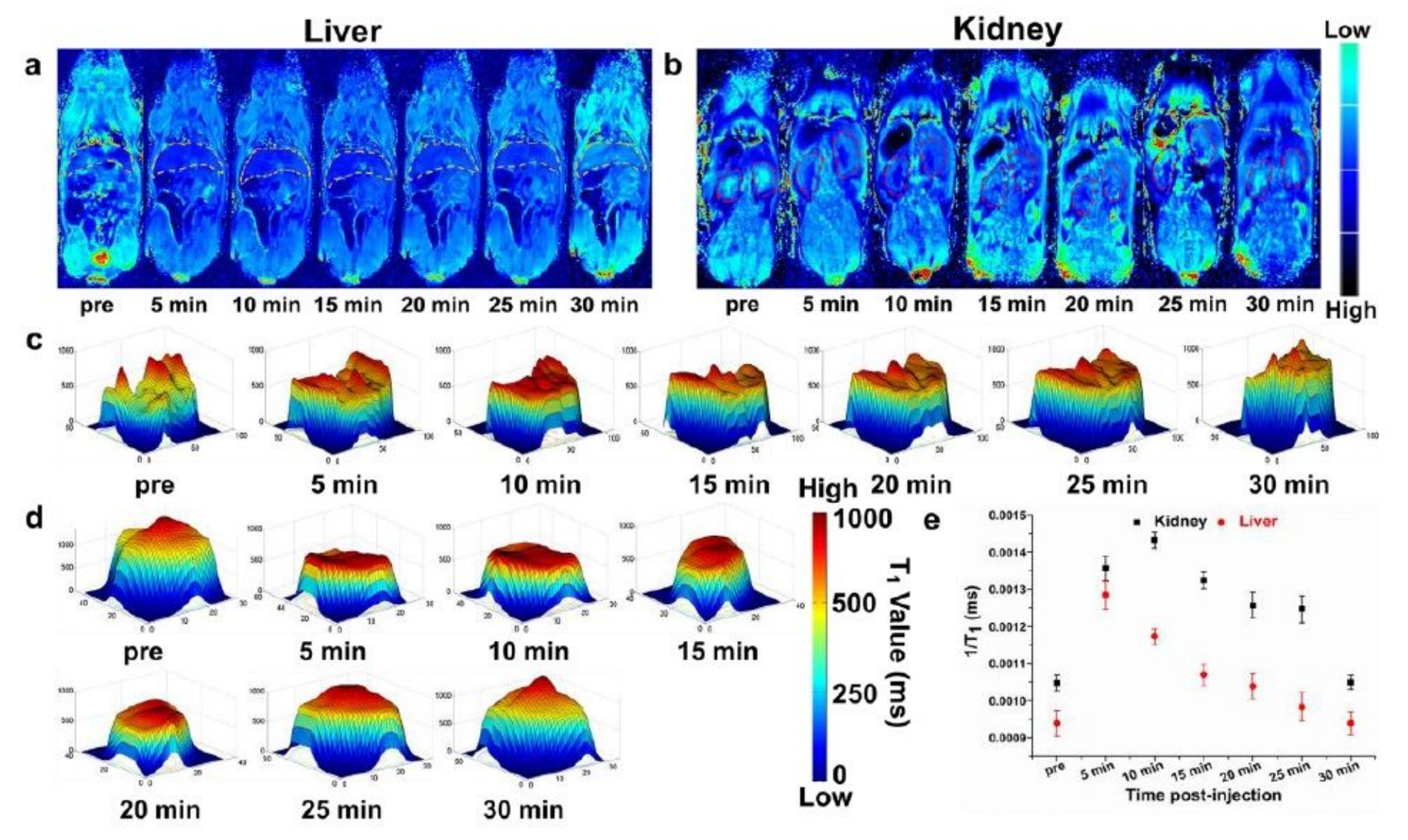

Figure 4

T 1 mapping imaging of liver a and kidney $b$ after injection of Branched pDHPMA mPEG Ppa PROXYL. The liver and kidney were labeled with yellow and red dashed lines, respectively. The darker blue signals in the liver and kidney suggest s harper enhancement in the MR images. The corresponding $T 1$ values were $s p$ atially displayed in the liver $c$ and kidney $d$ after injection of Branched pDHPMA mPEG Ppa PROXYL at different durations. e The 1/T 1 values for the liver and kidney were quantitatively analyzed ( $p$ $<0.05)$. 


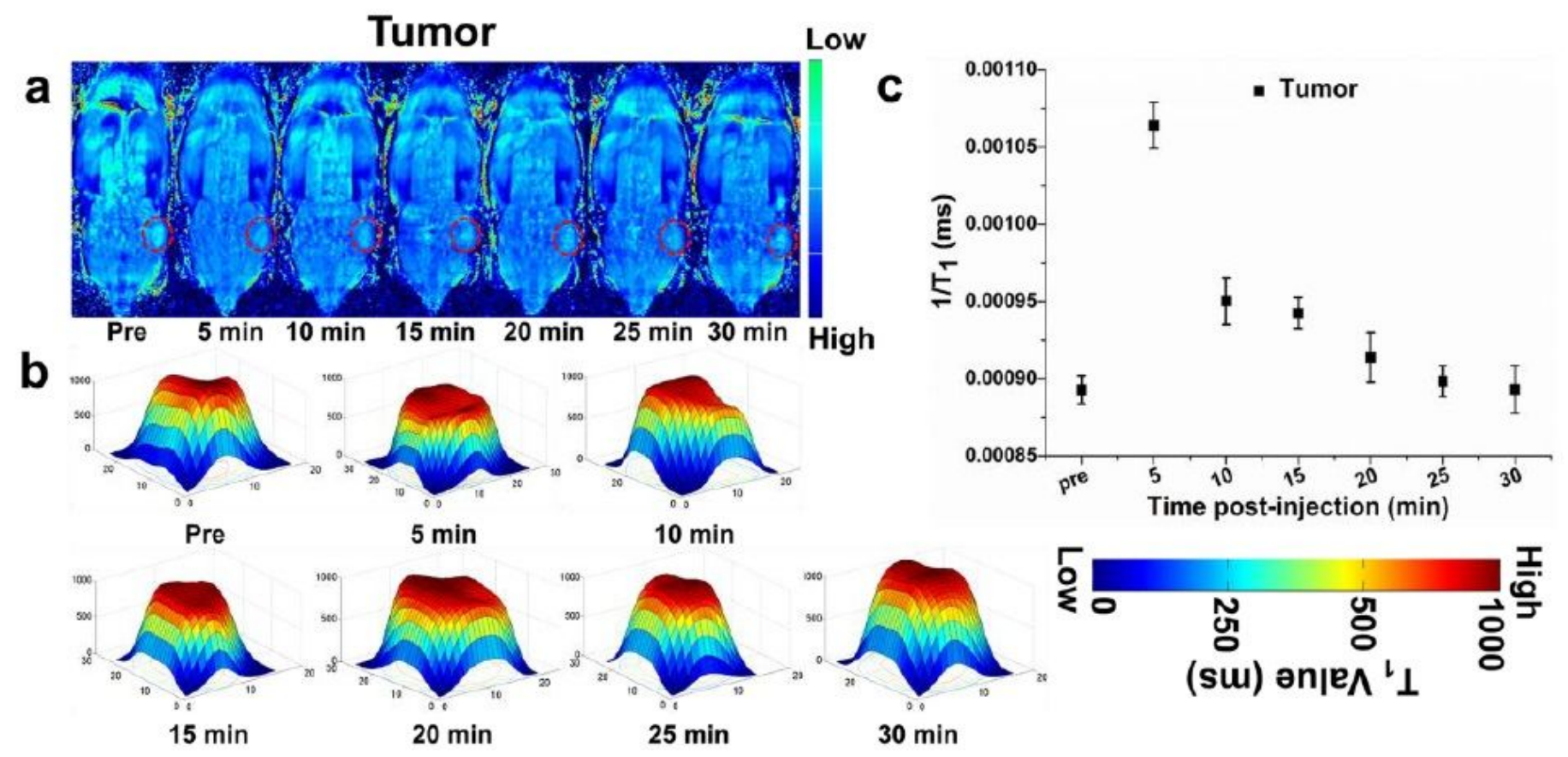

\section{Figure 5}

T 1 mapping imaging of tumor by Branched pDHPMA m PEG Ppa PROXYL a . The tum or was labeled with red lines, and darker blue signals in the tumor suggest sharper enhancement in the MR images. The corresponding $T 1$ values were spatially displayed in the tumor after injection of Branched pDHPMA mPEG Ppa PROXY L b at different durations. $c$ The $1 / T 1$ values of two tumor groups were quantitatively analyzed $(p<0.05)$. 


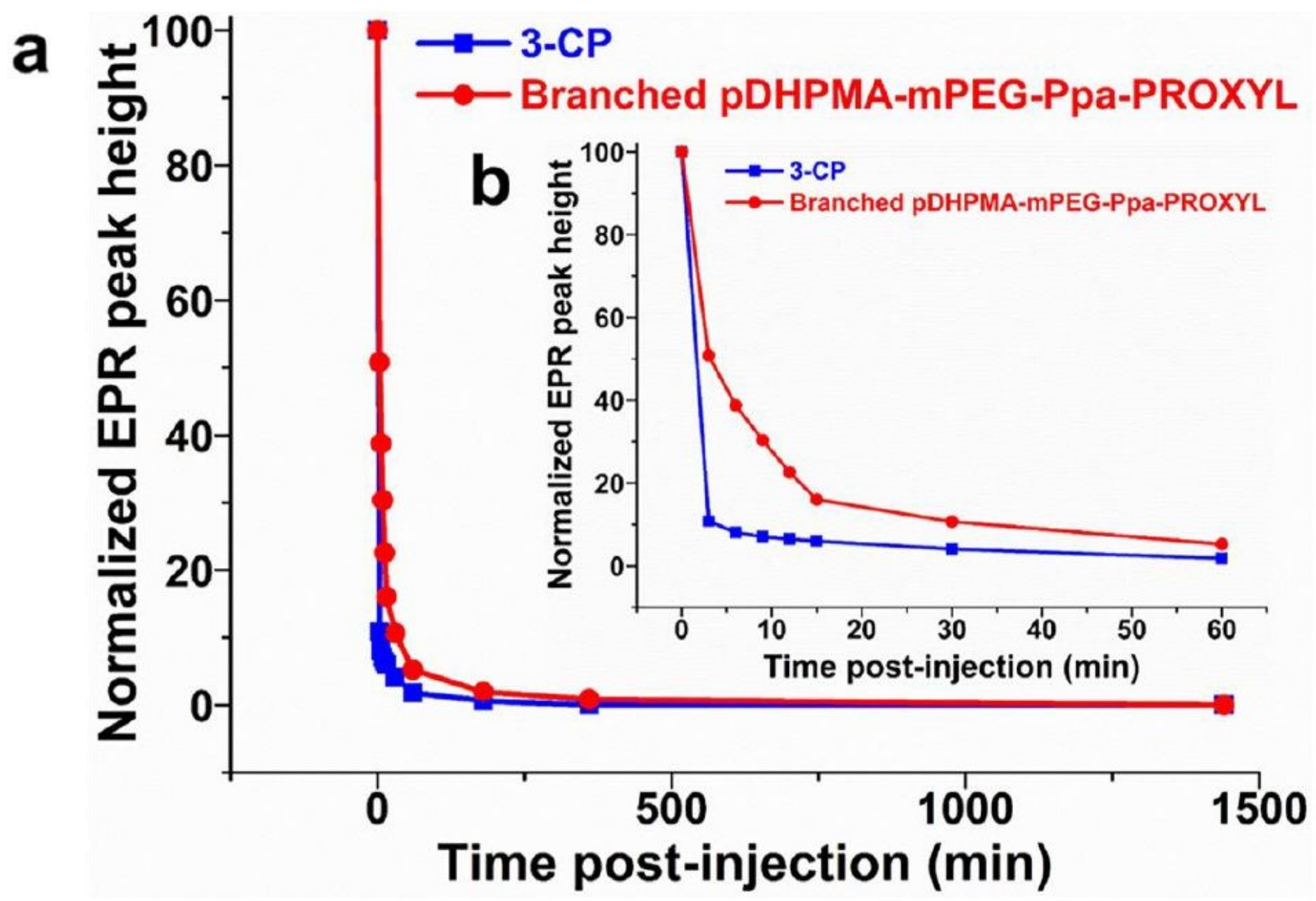

Figure 6

a Nitroxides concentration distribution in vivo for $24 \mathrm{~h}$ after injection of Branched pDHPM A mPEG Ppa PROXYL and $3 \mathrm{CP}$ and $\mathrm{b}$ nitroxides concentration changes within $1 \mathrm{~h}$. 




Figure 7

CLSM images of Branched pDHPMA mPEG Ppa PROXYL incubated with 4T1 cells for $1 \mathrm{~h}, 2 \mathrm{~h}$, and $6 \mathrm{~h}$. 
a
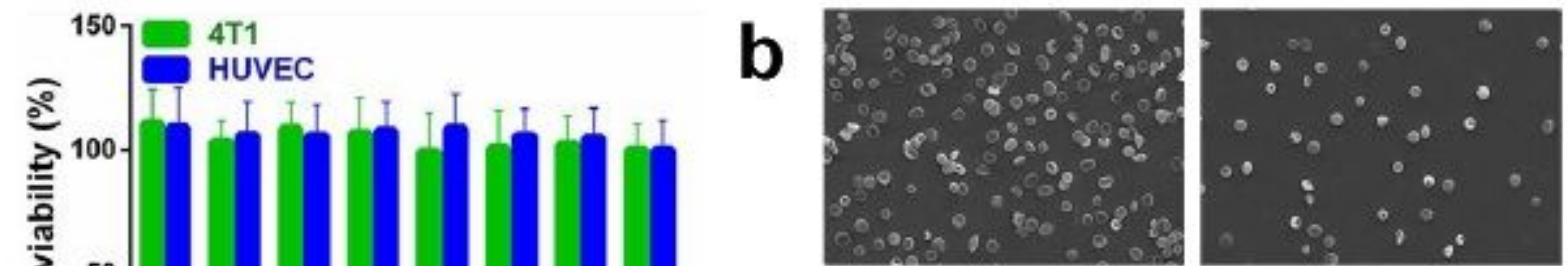

PBS

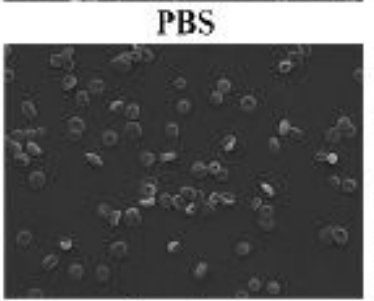

$2 \mathrm{mg} / \mathrm{mL}$

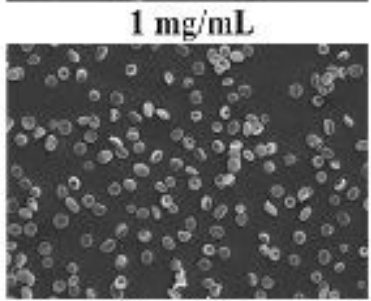

$5 \mathrm{mg} / \mathrm{mL}$

C

\section{Concentrations}
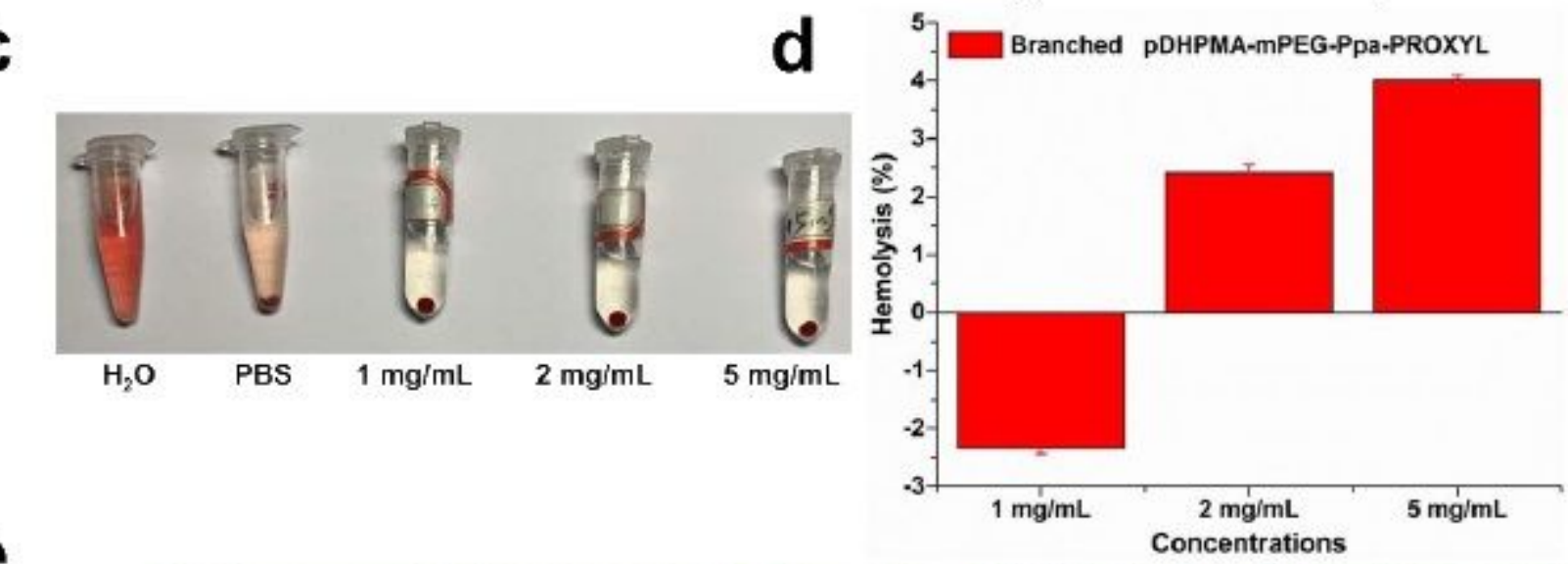

e
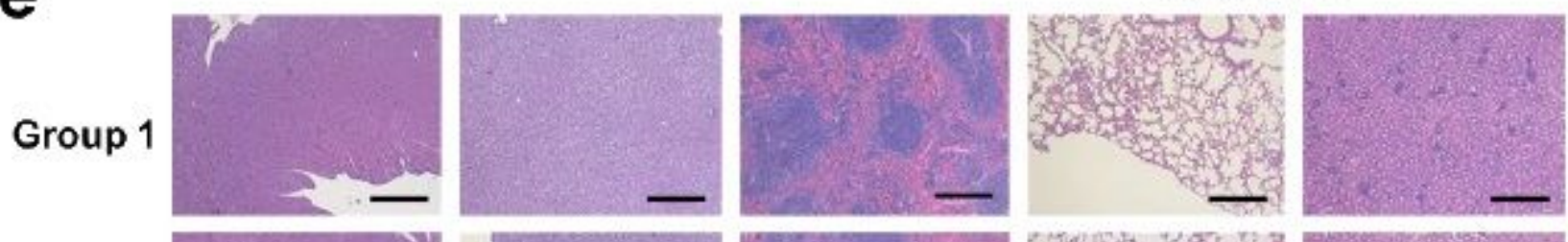

Group 2
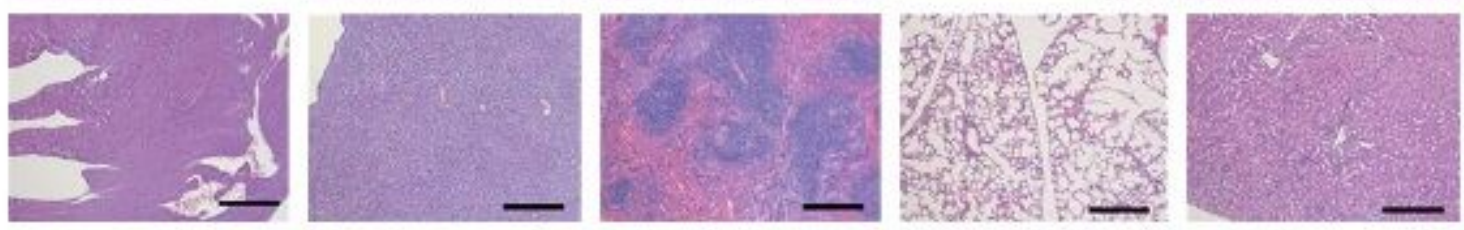

Group 3
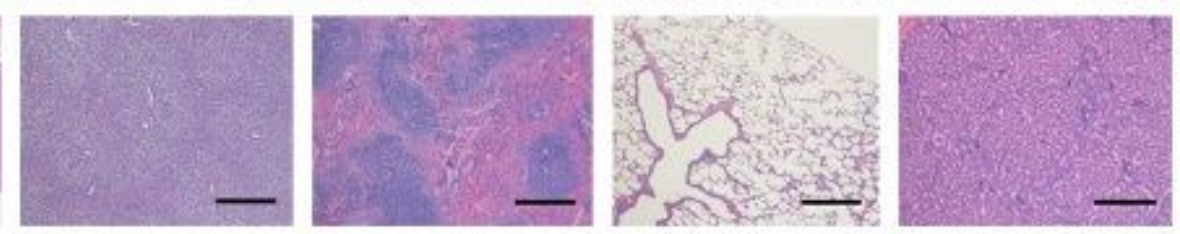

\section{Figure 8}

a Cell viability of $4 \mathrm{~T} 1$ cells and HUVEC cells after incubating with Branched pDHPMA mPEG Ppa PROXYL for $24 \mathrm{~h}$. $b$ The effects of PBS, $1 \mathrm{mg} / \mathrm{mL}, 2 \mathrm{mg} / \mathrm{mL}$, and $5 \mathrm{mg} / \mathrm{mL}$ Branched pDHPMA mPEG Ppa PROXYL on erythrocy te aggregation and morphology. $\mathrm{c}$ Red blood cell hemolysis of $\mathrm{Br}$ blood cell hemolysis of Branched pDHPMAanched pDHPMA-mPEGmPEG-PpaPpa-PROXYL. PROXYL. dd Hemolysis rates of Hemolysis rates of Branched pDHPMABranched pDHPMA--mPEGmPEG--PpaPpa--PROXYPROXYL at different concentrations. $L$ at different concentrations. ee Histological images of Histological images of 
mice 1 day after injection mice 1 day after injection of saline (Group 1), 3of saline (Group 1), 3-CP (Group

2) and Branched CP (Group 2) and Branched pDHPMApDHPMA--mPEGmPEG-PpaPpa--PROXYL (Group

3). Scale bar: $10 \mu \mathrm{m}$. PROXYL (Group 3). Scale bar: $10 \mu \mathrm{m}$.

\section{Supplementary Files}

This is a list of supplementary files associated with this preprint. Click to download.

- GraphicalAbstract.jpg

- SupportingInformation.doc 